\title{
Vitamin D and Multiple Sclerosis: A Comprehensive Review
}

\author{
Martina B. Sintzel $\cdot$ Mark Rametta $\cdot$ Anthony T. Reder
}

Received: October 10, 2017 / Published online: December 14, 2017

(C) The Author(s) 2017. This article is an open access publication

\begin{abstract}
Numerous observational studies have suggested that there is a correlation between the level of serum vitamin $\mathrm{D}$ and MS risk and disease activity. To explore this hypothesis, a literature search of large, prospective, observation studies, epidemiological studies, and studies using new approaches such as Mendelian randomization was conducted. Available data and ongoing research included in this review suggest that the level of serum vitamin $\mathrm{D}$ affects the risk of developing MS and also modifies disease activity in MS patients. Newer Mendelian randomization analyses suggest there is a causal relationship between low vitamin $\mathrm{D}$ level and the risk of MS. Post-hoc evaluations from two phase 3 studies, BENEFIT and BEYOND, support the findings of observational trials. Study
\end{abstract}

Enhanced content To view enhanced content for this article go to http://www.medengine.com/Redeem/ F5FCF060794BDA24.

M. B. Sintzel

Medical Communication Services, Erlenbach,

Zurich, Switzerland

M. Rametta

Bayer HealthCare Pharmaceuticals, Whippany, NJ, USA

\section{A. T. Reder $(\square)$}

Department of Neurology, University of Chicago, Chicago, IL, USA

e-mail: areder@neurology.bsd.uchicago.edu limitations identified in this review recognize the need for larger controlled clinical trials to establish vitamin D supplementation as the standard of care for MS patients. Though there is increasing evidence indicating that lower vitamin D levels are associated with increased risk of MS and with greater clinical and brain MRI activity in established MS, the impact of vitamin D supplementation on MS activity remains inadequately investigated.

Keywords: Autoimmune disease; Health outcomes; Mendelian randomization; Multiple sclerosis; Optic neuritis; Pregnancy; Relapsingremitting MS (RRMS); Supplementation; Vitamin D

\section{INTRODUCTION}

Knowledge of the widespread effects of vitamin $\mathrm{D}$ on skeletal and non-skeletal functions, including immune functions, has developed considerably over the past 3 decades. Higher levels of vitamin $\mathrm{D}$ are associated with reduced risk for developing multiple sclerosis (MS), and with reduced clinical activity in established MS, including decreased risk of relapse and reduction in disease activity on brain MRI $[1,2]$. Vitamin D supplementation may diminish the risk of MS in the general population, as well as in children of mothers supplemented before 
and during pregnancy [3]. In the information that follows, we will summarize the available data on vitamin $D$, with a focus on vitamin D's effects on the risk of onset of MS and on the disease course of MS.

\section{Sources, Metabolism, and Biological Functions of Vitamin D}

Vitamin D is a lipid-soluble vitamin, but acts like a hormone. Unlike a vitamin, which is an essential organic compound that cannot be synthesized by the body and must be ingested, vitamin $\mathrm{D}$ can be synthesized [4]. The active form of vitamin $\mathrm{D}, 1,25$-dihydroxyvitamin $\mathrm{D}$ $\left(1,25[\mathrm{OH}]_{2} \mathrm{VD}\right)$, also known as calcitriol (Fig. 1) [5] has chemical similarities to typical hormones such as testosterone, estrogen, and cortisol [6]. The main sources of vitamin D are sunlight, diet, and supplementation (Fig. 2) [7]. UVB in the 290-315-nm range photolyses 7-dehydrocholesterol in the skin to form previtamin D3, which then isomerizes to vitamin D3 or cholecalciferol [8]. Foods rich in vitamin D include fatty fish (e.g., salmon, mackerel), cod liver oil, egg yolk, and shiitake mushrooms. The plant form of vitamin D is called vitamin D2 or ergocalciferol [9]. Cholecalciferol and ergocalciferol are also available from fortified foods (e.g., milk, cereal, some orange juice, and cheeses) and vitamin supplements.

Relative to sun exposure, diet is a poor source of vitamin D, providing only 40-400 IU per food serving, whereas whole-body UVB
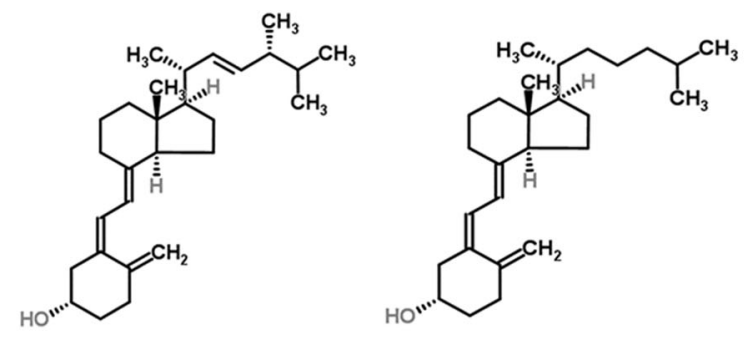

a Vitamin D2

b Vitamin D3

Fig. 1 Chemical structures of the physiologically inactive vitamin D2 (a) and vitamin D3 (b); the main circulating vitamin D3 intermediate, 25-hydroxyvitamin D exposure for $20 \mathrm{~min}$ for a light-skinned person during the summer months will produce upwards of $10,000 \mathrm{IU}$ of vitamin D [7, 10]. However, UVB exposure and vitamin D production through the skin may be reduced with increased skin pigmentation, age, use of sunscreen, and environmental factors such as winter season, high latitude, pollution, cloud cover, and ozone levels [7]. For instance, sun exposure during most of the winter at latitudes above $\sim 33^{\circ}$ North (e.g., Atlanta, GA, USA; Casablanca, Morocco) and below 33 degrees South (e.g., Santiago, Chile; New South Wales, Australia; Southern Cape of Africa) provides minimal, if any, vitamin D production [11].

Both forms of vitamin D, cholecalciferol, and ergocalciferol are biologically inactive and undergo an enzymatic transformation in the liver to $25(\mathrm{OH}) \mathrm{D}$ (calcidiol). Stimulated by parathyroid hormone, $25(\mathrm{OH}) \mathrm{D}$ goes through a second hydroxylation in the kidney or other tissues to $1,25(\mathrm{OH})_{2} \mathrm{VD}$ (also known as calcitriol if derived from vitamin D3), which is the active metabolite (Figs. 1 and 2) [5, 7]. 1,25(OH) $2 \mathrm{VD}$ has a half-life of several hours, while $25(\mathrm{OH}) \mathrm{D}$ has a relatively long half-life (20-60 days), and thus more accurately exemplifies the overall vitamin $\mathrm{D}$ stores in the body. This supports the standard practice of measuring $25(\mathrm{OH}) \mathrm{D}$ in serum, and represents an integrated measure of vitamin $\mathrm{D}$ derived from both UVB exposure and diet. As a side note, most assays that evaluate $25(\mathrm{OH}) \mathrm{D}$ do not discriminate between the original forms of vitamin D (vitamin D3 or D2).

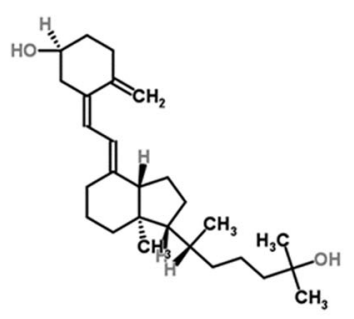

C 25-hydroxyvitamin D

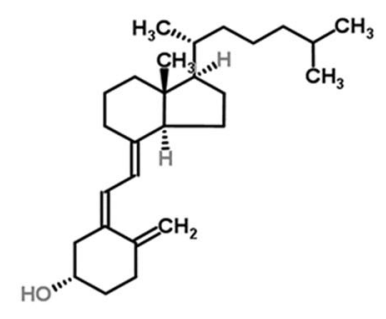

d 1,25-dihydroxyvitamin D

$(25[\mathrm{OH}] \mathrm{D})(\mathbf{c})$; and the bioactive vitamin D3 metabolite 1,25-dihydroxyvitamin $\mathrm{D}\left(1,25[\mathrm{OH}]_{2} \mathrm{VD}\right)(\mathbf{d})$, or calcitriol if derived from vitamin D3 [5] 


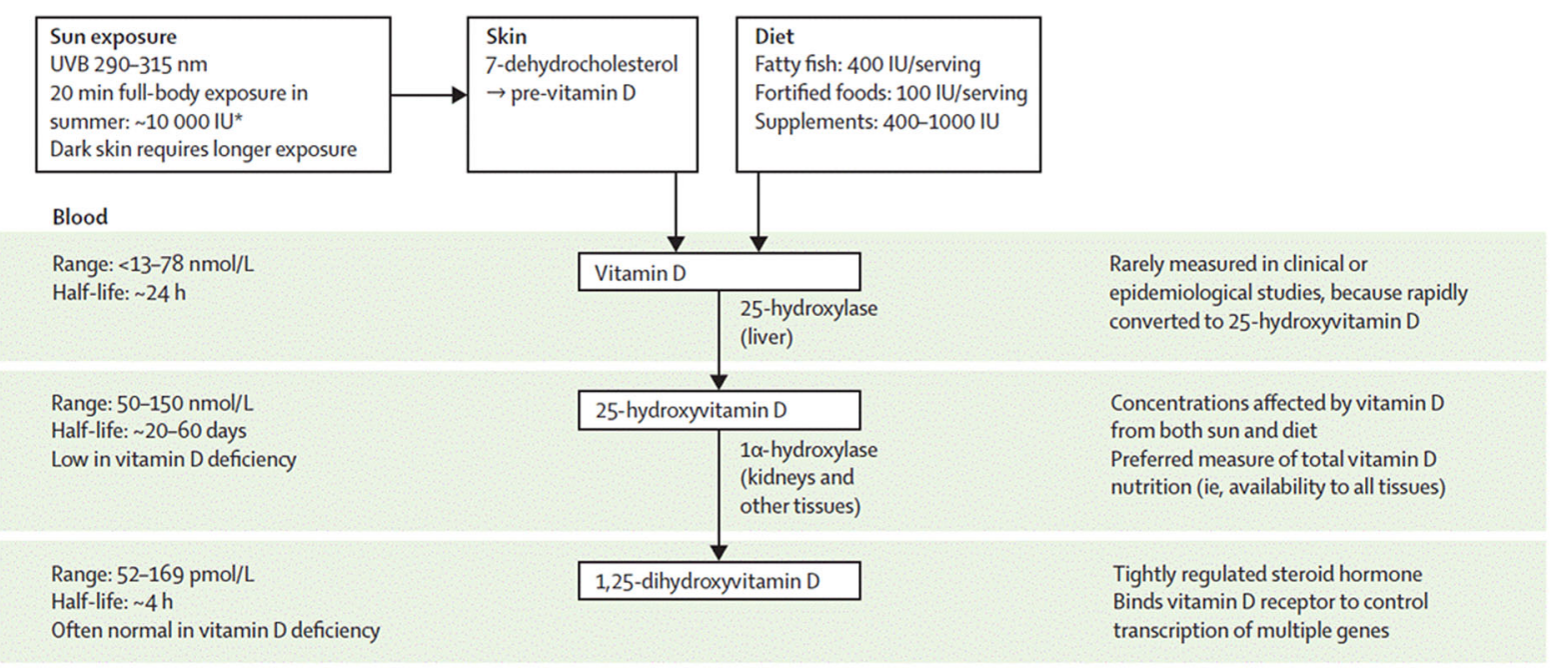

Fig. 2 Sources and metabolism of vitamin D: The main sources of vitamin D are sunlight, diet, and supplementation. The primary forms of vitamin D are biologically inactive and need for their activation two hydroxylation steps in the liver and kidney. The hormonally active final product is 1,25-dihydroxyvitamin $\mathrm{D}\left[1,25(\mathrm{OH})_{2} \mathrm{VDO}\right]$.

However, the latter is usually a minor component because natural sources of ergocalciferol are scarce, and ergocalciferol is more rapidly catabolized than cholecalciferol [7].

The active metabolite $1,25(\mathrm{OH})_{2} \mathrm{VD}$ is released into the bloodstream and transported in the blood. It binds to the vitamin D binding protein in blood and on the surface of target tissues. $1,25(\mathrm{OH})_{2} \mathrm{VD}$ mediates its biological effects by binding to intracellular vitamin $\mathrm{D}$ receptor (VDR), which then recruits cofactors to form a transcriptional complex that binds to vitamin D response elements [12]. This association regulates the expression of at least 500 genes that drive a variety of physical functions [7]. The VDR is found in almost all human tissues, not just those participating in the classic actions of vitamin $\mathrm{D}$, such as bone, gut, and kidney. The non-classic actions of VDR can be allocated to three main categories: regulation of hormone secretion, regulation of immune function, and regulation of cellular proliferation and differentiation [12].

Vitamin D deficiency has been classically attributed to bone health. In the early 1900s, rickets, a consequence of vitamin D deficiency,
$1,25(\mathrm{OH})_{2} \mathrm{VD}$ has a half-life of several hours, while the intermediate vitamin $\mathrm{D}$ form 25-hydroxyvitamin $\mathrm{D}$ $[25(\mathrm{OH}) \mathrm{D}]$ has a relatively long half-life (20-60 days), and thus more accurately exemplifies the overall vitamin $\mathrm{D}$ stores in the body [7]. Reprinted from [7], with permission from Elsevier

was very common among children in industrialized cities, and observations were made that sunlight exposure or cod liver oil may help to prevent this condition [10]. Other musculoskeletal consequences of vitamin D deficiency include secondary hyperparathyroidism, increased bone turnover, bone loss, and risk of low-trauma fractures. Today, we understand that VDR is widely distributed throughout the human body and involved in many biological functions. Vitamin D deficiency has been associated with numerous diseases including cancers, cardiovascular diseases, type 2 diabetes mellitus, infectious diseases, mental disorders, and autoimmune disorders such as type 1 diabetes mellitus, Crohn's disease, and MS [10, 13]. These diseases are all linked to vitamin D levels that are sufficient to prevent rickets, but are still suboptimal. Curiously, as rickets is no longer a problem, one might assume that the vitamin $\mathrm{D}$ deficiency problem is also no longer an issue. However, now that we know that autoimmunity may be related to low vitamin D levels, and that the incidence of autoimmune diseases has increased, we must consider if there is a higher vitamin D threshold related to autoimmunity, 
or if the environment changed since the Industrial Revolution.

\section{Roles of Vitamin D in Immunity}

Since multiple sclerosis (MS) is considered an autoimmune disease, it is of interest to review briefly the potential effects of vitamin D related to immune function. The active form of vitamin D plays an essential role in lymphocyte activation and proliferation, T-helper cell differentiation, tissue-specific lymphocyte homing, the production of specific antibody isotypes, and regulation of the immune response [14]. Targeted immune cell types include macrophages, dendritic cells, and $\mathrm{T}$ and B cells. Mora and colleagues (Fig. 3) [14] summarized the roles and effects of vitamin D on these immune cell types [14]:

- Macrophages and dendritic cells (DCs) constitutively express VDRs, whereas VDR expression in $\mathrm{T}$ cells is upregulated only after activation.
- In macrophages and monocytes, $1,25(\mathrm{OH})_{2} \mathrm{VD}$ positively impacts its own effects by increasing the expression of VDR and the cytochrome $\mathrm{P} 450$ protein, CYP27B1.

- Certain Toll-like receptor (TLR)-mediated signals also can increase the expression of VDRs.

- The active form of vitamin D induces monocyte proliferation and the expression of interleukin-1 (IL-1) and cathelicidin (an antimicrobial peptide) by macrophages, contributing to innate immune responses to some bacteria.

- $1,25(\mathrm{OH})_{2} \mathrm{VD}$ decreases DC maturation, inhibiting upregulation of the expression of MHC class II, CD40, CD80, and CD86. In addition, it decreases IL-12 production by DCs while inducing the production of IL- 10 .

- In T cells, $1,25(\mathrm{OH})_{2} \mathrm{VD}$ reduces the production of IL-2, IL-17, and interferon- $\gamma$ (IFN $\gamma$ ) and attenuates the cytotoxic activity and proliferation of CD4+ and CD8+ T cells.

- The active metabolite of vitamin D might also promote the development of forkhead

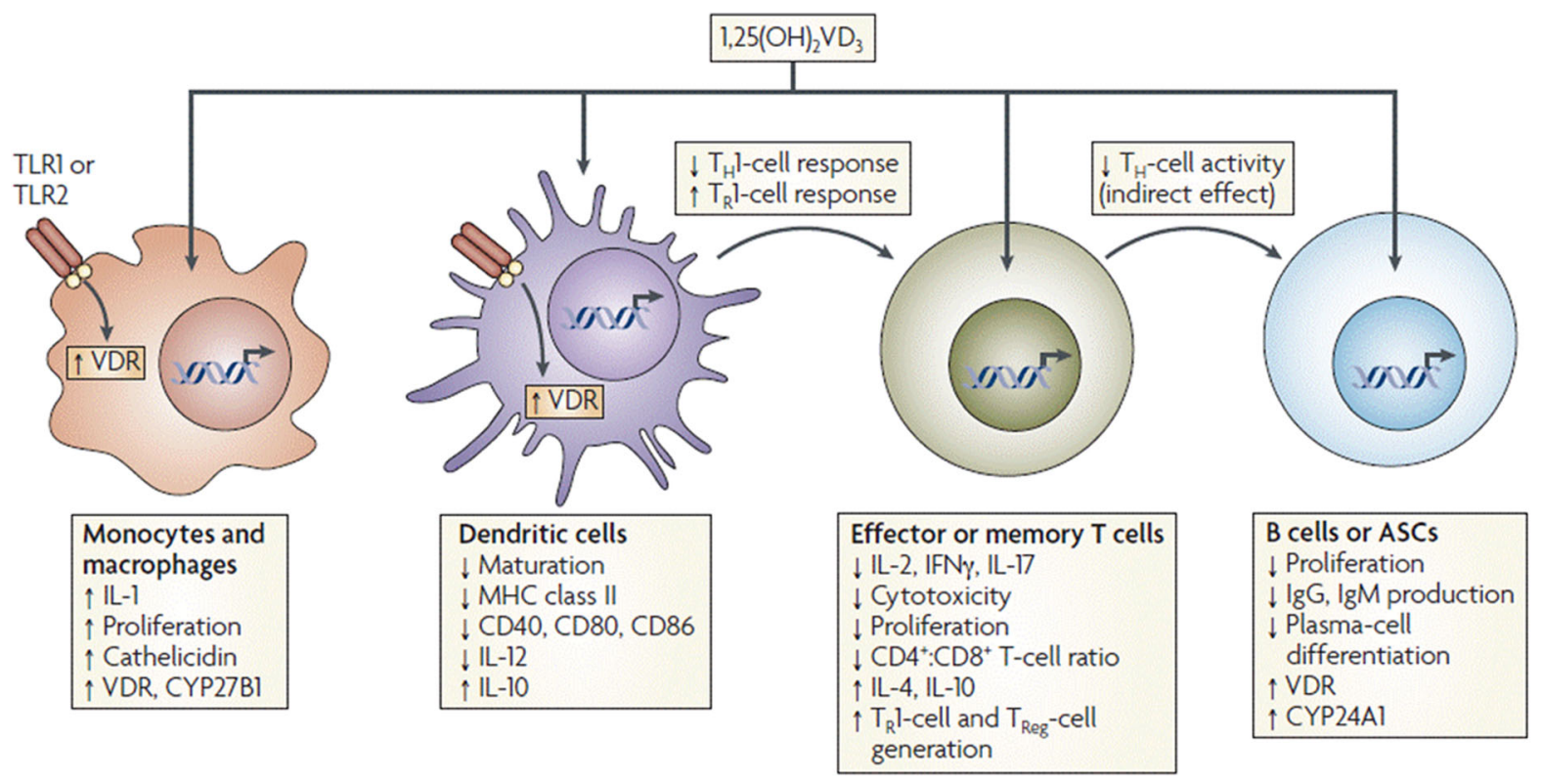

Fig. 3 Potential mechanisms of vitamin D immunomodulation: systemic 1,25(OH)2VD3 affects several immunecell types, including macrophages, dendritic cells (DCs), T and B cells. Macrophages and DCs constantly express

vitamin $\mathrm{D}$ receptor (VDR), whereas VDR expression in $\mathrm{T}$ cells is only upregulated following activation. Reprinted by permission from Macmillan Publishers Ltd: [14] 
Table 1 Definition of vitamin D status [as measured by blood levels of $25(\mathrm{OH}) \mathrm{D}$ ] and daily vitamin D intake recommended by the Institute of Medicine (IOM) and the Endocrine Society $[4,11,13,16]$

\begin{tabular}{lll}
\hline & Institute of medicine & Endocrine society \\
\hline Vitamin D status & & \\
"Deficient" & - & $\leq 20 \mathrm{ng} / \mathrm{mL}(\leq 50 \mathrm{nmol} / \mathrm{L})$ \\
"Insufficient" & - & $21-29 \mathrm{ng} / \mathrm{mL}(51-74 \mathrm{nmol} / \mathrm{L})$ \\
"Sufficient" & $20 \mathrm{ng} / \mathrm{mL}(50 \mathrm{nmol} / \mathrm{L})$ & $\geq 30 \mathrm{ng} / \mathrm{mL}(\geq 75 \mathrm{nmol} / \mathrm{L})$ \\
"Ideal" & - & $40-60 \mathrm{ng} / \mathrm{mL}(100-150 \mathrm{nmol} / \mathrm{L})$ \\
Considered "safe" & - & $\leq 100 \mathrm{ng} / \mathrm{mL}(\leq 250 \mathrm{nmol} / \mathrm{L})$ \\
Daily vitamin D intake recommendations (upper limits) & \\
Infants & $400 \mathrm{IU} /$ day (1000-1500 IU/day) & $400-1000 \mathrm{IU} /$ day $(2000 \mathrm{IU} /$ day $)$ \\
Children & $600 \mathrm{IU} /$ day (2500-3000 IU/day) & $600-1000 \mathrm{IU} /$ day $(4000 \mathrm{IU} /$ day $)$ \\
Adults & $600 \mathrm{IU} /$ day (4000 IU/day), 800 IU/day for seniors & $1500-2000 \mathrm{IU} /$ day $(10,000 \mathrm{IU} /$ day $)$ \\
\hline
\end{tabular}

box protein 3 (FOXP3)+ regulatory $T\left(T_{\mathrm{Reg}}\right)$ cells and IL-10-producing $T$ regulatory type 1 (TR1) cells.

- $1,25(\mathrm{OH})_{2} \mathrm{VD}$ blocks B cell proliferation, plasma cell differentiation, and immunoglobulin production.

Notable in the context of this review, many of the mechanisms of vitamin D on immune processes have similarities to mechanisms described for interferon-beta [15].

\section{Definition of Vitamin D Deficiency and Targeted Levels of Vitamin D}

The clinical definition of vitamin D deficiency and what constitutes optimal levels has been the subject of debate. Two organizations, the Institute of Medicine (IOM) and the Endocrine Society, have released separate recommendations regarding vitamin $\mathrm{D}$ requirements $[4,11,16]$. Blood levels of $25(\mathrm{OH}) \mathrm{D}$ as suggested by the IOM and the Endocrine Society and the recommended dietary allowances (RDAs) by both organizations are provided in Table 1 $[4,11,16]$.

The foundational basis for the recommendations by these two organizations are fundamentally different. The IOM guidelines based their recommendation on a population model and focused on bone health (calcium absorption, bone mineral density, and osteomalacia/rickets) aiming to prevent vitamin D deficiency in $97.5 \%$ of the general population. Based on the model applied, no evidence was found that a serum $25(\mathrm{OH}) \mathrm{D}$ concentration $>20 \mathrm{ng} / \mathrm{mL} \quad(50 \mathrm{nmol} / \mathrm{L})$ had beneficial effects at a population level. Therefore, the IOM concluded that the daily requirements for vitamin $\mathrm{D}$ were adequate to reach the "sufficient" $25(\mathrm{OH}) \mathrm{D}$ level of $20 \mathrm{ng} / \mathrm{mL}(50 \mathrm{nmol} / \mathrm{L})$, and that these levels were generally attained by most of the population $[4,16]$.

Alternatively, the Endocrine Society concluded that a level of $20 \mathrm{ng} / \mathrm{mL}(50 \mathrm{nmol} / \mathrm{L})$ was not sufficient. The Endocrine Society based their recommendations on a medical model taking into consideration available evidence on skeletal and extraskeletal effects of vitamin D, in addition to the few negative studies. Moreover, they took into consideration the low toxicity potential of vitamin $\mathrm{D}$ supplementation. In their view, serum $25(\mathrm{OH}) \mathrm{D}$ levels of $\geq 30 \mathrm{ng} / \mathrm{mL}$ $(\geq 75 \mathrm{nmol} / \mathrm{L})$ are "sufficient" for children and adults, levels of $40-60 \mathrm{ng} / \mathrm{mL}(100-150 \mathrm{nmol} / \mathrm{L})$ are "ideal" (considering assay variability), and levels of up to $100 \mathrm{ng} / \mathrm{mL}(250 \mathrm{nmol} / \mathrm{L})$ could be considered "safe" [11, 13].

The Endocrine Society advocates for screening and corrective action for individuals at risk of vitamin D deficiency. Such individuals 
include African American and Hispanic children and adults; pregnant and lactating women; older adults with a history of falls or nontraumatic fractures; obese children and adults $\left(\mathrm{BMI}>30 \mathrm{~kg} / \mathrm{m}^{2}\right)$; and patients with musculoskeletal diseases, chronic kidney disease, hepatic failure, malabsorption syndromes, and some lymphomas [11]. Furthermore, the group recommends supplementation at suggested daily intake and tolerable-upper-limit levels, depending on age and clinical circumstances (Table 1) $[4,11,13,16]$.

\section{Supplemental Vitamin D}

The recommended dietary allowance (RDA) for vitamin $\mathrm{D}$ and the tolerable-upper-limit levels vary with age and under certain circumstances such as those involving pregnancy, obesity, or comorbidities. A daily dose of 600-800 IU should satisfy the requirements for optimal bone health [16], but a higher intake (1000-2000 IU) is needed to achieve and maintain 25(OH)D levels $>30 \mathrm{ng} / \mathrm{mL} \quad(75 \mathrm{nmol} / \mathrm{L})$ [11]. Vitamin D supplements can be administered daily, weekly, monthly, or every 4 months to reach an adequate serum $25(\mathrm{OH}) \mathrm{D}$ concentration. For cases of extreme vitamin D deficiency, a bolus application of vitamin D has been proposed, but a steady-state serum $25(\mathrm{OH}) \mathrm{D}$ concentration is more likely to be maintained by more frequent, lower doses of vitamin D [13]. Vitamin D3 (cholecalciferol) is widely preferred over vitamin D2 (ergocalciferol), as it has proven to be the more potent form of vitamin $D$ in all primate species, including humans [17]. Vitamin D supplementation at doses of 1500-2000 IU/day for adults as suggested by the Endocrine Society appears to be well tolerated, with relatively minor concerns about toxicity for most patients [11]. Caution should be exercised in patients with impairment of renal function, cardiovascular diseases, chronic granuloma-forming disorders (sarcoidosis or tuberculosis), or chronic fungal infections. Some patients with lymphoma have activated macrophages that produce $1,25(\mathrm{OH})_{2} \mathrm{VD}$ in an unregulated fashion.

\section{Vitamin D Safety Risks and Vitamin D Intoxication}

$1,25(\mathrm{OH})_{2} \mathrm{VD}$ stimulates intestinal calcium absorption [18]. Without vitamin D, only $10-15 \%$ of dietary calcium and about $60 \%$ of phosphorus are absorbed. Vitamin D sufficiency enhances absorption of calcium by $30-40 \%$ and phosphorus by $80 \%[11,19,20]$. Vitamin D intoxication is characterized by hypercalcemia, hypercalciuria, and hyperphosphatemia and in the long term, can lead to soft tissue and vascular calcification and nephrolithiasis [13]. After review of available literature, the Endocrine Practice Guidelines Committee concluded that vitamin $\mathrm{D}$ toxicity is a rare event caused by inadvertent or intentional ingestion of excessively high amounts of vitamin D [11]. Concerns were expressed for people with $25(\mathrm{OH}) \mathrm{D}$ levels of $150 \mathrm{ng} / \mathrm{mL}(375 \mathrm{nmol} / \mathrm{L})$ or higher, when daily doses of vitamin D exceed 10,000 IU or when high intake of vitamin $\mathrm{D}$ is combined with high intake of calcium. A dose-ranging study reported that $10,000 \mathrm{IU} /$ day of vitamin D3 for 5 months in healthy men did not alter their serum calcium or their urinary calcium excretion, which is the most sensitive indicator for potential vitamin D intoxication [21]. However, there is a paucity of evidence supporting the use of higher levels of vitamin $\mathrm{D}$ over a prolonged time [11].

Safety findings in three studies conducted in patients with MS using doses of vitamin D above 10,000 IU/day are noteworthy. One open-label trial of vitamin $\mathrm{D}$ in patients with MS evaluated the safety of a dose-escalation protocol from 4000 to 40,000 IU/day (mean of 14,000 IU/day). Concomitantly, patients received $1200 \mathrm{mg}$ of calcium per day $v s$. a control group (allowed up to 4000 IU/day of vitamin $\mathrm{D}$ and supplemental calcium if desired) over 1 year [22]. All calcium-related measures within and between groups were normal. Despite a mean peak 25(OH)D level of $165 \mathrm{ng} /$ $\mathrm{mL}(413 \mathrm{nmol} / \mathrm{L})$, no significant adverse events occurred. The safety results were in line with a previously conducted, smaller study in 12 patients with MS also using doses of up to $40,000 \mathrm{IU}$ [23]. In the third study, 15 patients with relapsing-remitting MS (RRMS) were 
supplemented with 20,000 IU/day of vitamin D3 for 12 weeks [24]. The median vitamin D level increased from $50 \mathrm{nmol} / \mathrm{L}$ (range: $31-175 \mathrm{nmol} / \mathrm{L}$ ) at week $0-380 \mathrm{nmol} / \mathrm{L}$ (range: $151-535 \mathrm{nmol} / \mathrm{L})$ at week $12(P<0.001)$. All patients completed the observation period without side effects, hypercalcemia, or hypercalciuria [24].

There are cases in the literature in which exceptionally high doses (considerably above the daily upper limit of 10,000 IU) led to vitamin D toxicity:

- Bell and coworkers described a 67-year-old woman with vitamin D intoxication. Because of a compounding error by the pharmacy, the woman had taken $600,000 \mathrm{IU}$ (rather than the intended $600 \mathrm{IU})$ of cholecalciferol daily for more than 3 years, leading to reversible hypercalcemia and partially reversible renal impairment [25].

- Fragoso and colleagues reported considerable vitamin D toxicity in 21 MS patients who were exposed to levels ranging from $8000 \mathrm{IU} /$ day to extremely high, supra-physiological doses of 150,000 IU/day (average 87,000 IU) [26].

In order to assess the correlation between vitamin D and MS, a literature search of large, prospective, observational studies, epidemiological studies, and studies using new approaches such as Mendelian randomization was conducted.

\section{Compliance and Ethics Guidelines}

This article is based on previously conducted studies, and as such, does not involve any new studies of human or animal subjects performed by any of the authors.

\section{VITAMIN D LEVELS AND MS SUSCEPTIBILITY}

Since vitamin D was proposed as an important factor in MS development in the 1970s, numerous experimental and epidemiologic studies have been conducted to answer key questions such as Does vitamin D prevent MS? How does vitamin D impact MS activity? and Can vitamin $D$ supplementation favorably alter the course of MS? Observational study data does suggest that adequate vitamin D levels may reduce the risk of MS and affect the course of the disease. However, study limitations restrict the extent to which inverse associations can be attributed to vitamin $\mathrm{D}$, and additional studies are needed to further understand the nature of this association [2].

\section{Epidemiologic Study Data}

Epidemiologic studies substantiate that the prevalence of MS is greater at higher latitudes and tends to peak in areas with the lowest exposure to ultraviolet light [27-32]. Additionally, to some degree, diets rich in vitamin D-containing oily fish may offset this risk $[27,28]$. In "historical" cohorts, the risk of MS decreased among people who migrate from higher to lower latitudes [33]. However, this latitudinal finding has appeared to decline in recent decades and may be linked to an increased trend towards avoiding sun exposure or staying indoors for longer portions of the day, even in warmer climates [7, 34].

An Australian case-control study examined whether leisure sun exposure, combined with $25(\mathrm{OH}) \mathrm{D}$ status impacts the risk of a first demyelinating event and whether this was related to a latitude gradient [35]. Independently, higher levels of sun exposure (past, recent, and cumulative), higher actinic skin damage and higher $25(\mathrm{OH}) \mathrm{D}$ levels were associated with significantly reduced risks of a demyelinating event. The investigators calculated that the differences in leisure sun exposure, serum $25(\mathrm{OH}) \mathrm{D}$ level, and skin type would additively account for a $32.4 \%$ increase in the incidence of first demyelinating events from the low to high latitude regions in Australia [35]. The independent association of sun exposure and MS risk suggests that UV light itself may influence MS risk. Partially supporting this is research that showed that experimental autoimmune encephalitis (EAE) could be prevented in mice through whole-body irradiation 
with UV light [36]. However, this research did not discriminate between vitamin D-related and nonrelated effects of UV light. The research did note that in the Northern Hemisphere, significantly more people with MS are born in May $(9.1 \%)$, when there is less sunlight during pregnancy than in November $(8.5 \%)$, when there is an increased amount of sunlight [37]. Some argue that this is an artifact of more births during certain months [38] though others disagree [39].

\section{Dietary Intake of Vitamin D and MS Risk}

Using data from two large cohorts of the Nurses' Health Study involving more than 187,000 women (including 300 who developed MS during the study), Munger and colleagues evaluated the association between calculated vitamin $\mathrm{D}$ intake from diet or supplements and the risk of developing MS [40]. Women who had a higher intake of dietary vitamin D (approximately 700 IU/day) had a 33\% lower incidence of MS compared with those with lower intake. In addition, women who used vitamin $\mathrm{D}$ supplements ( $\geq 400 \mathrm{IU} /$ day) had a $41 \%$ reduced risk of developing MS compared to non-users. Having higher levels of $25(\mathrm{OH}) \mathrm{D}$ (irrespective of dietary vitamin D intake) also seems to predict a lower risk of MS onset. Using a longitudinal study design, Munger and colleagues evaluated serum vitamin D levels derived from blood samples of seven million US military personnel. Those with 25(OH)D levels greater than $100 \mathrm{nmol} / \mathrm{L}$ (40 ng/mL) had a 62\% lower chance of subsequently developing MS [1].

\section{Vitamin D Levels During Pregnancy and MS Risk in Offspring}

The Finnish Maternity Cohort is a comprehensive registry, established in 1983, that includes more than 800,000 women and more than 1.5 million serum samples. This cohort also served as a basis for examining the association of vitamin D levels during pregnancy and MS risk [3]. One hundred ninety-three patients with a diagnosis of MS, whose mothers were captured in the registry and had an available serum sample from the pregnancy with the affected child, were matched with 326 controls. Vitamin $\mathrm{D}$ levels were low in both groups, but lower in the mothers of MS patients than in controls [34.6 nmol/L $\quad(13.9 \mathrm{ng} / \mathrm{mL}) \quad$ vs. $37.5 \mathrm{nmol} / \mathrm{L}$ $(15.0 \mathrm{ng} / \mathrm{mL}) ; P=0.006]$. Moreover, MS risk was $90 \%$ higher in the offspring of vitamin D-deficient mothers $[25(\mathrm{OH}) \mathrm{D}<30 \mathrm{nmol} / \mathrm{L}(12.0 \mathrm{ng} /$ $\mathrm{mL})$ ] compared with offspring of mothers who were not vitamin $\mathrm{D}$ deficient [relative risk, 1.90; 95\% confidence interval (CI), 1.20-3.01; $P=0.006$ [ [3]. These data suggest that insufficient vitamin D levels during pregnancy may increase the risk of MS [3].

The association between neonatal 25(OH)D status and risk of MS was examined in a large population-based case-control study using data from the nationwide Danish MS Registry and the Danish Newborn Screening Biobank (DNSB) [41]. Data from 521 patients with MS and 972 controls were investigated. The analysis by quintiles revealed individuals with the highest risk of MS were in the lowest quintile group of 25(OH)D $(<20.7 \mathrm{nmol} / \mathrm{L})$, and individuals the lowest risk were in the highest quintile group ( $\geq 48.9 \mathrm{nmol} / \mathrm{L}$ ); with an odds ratio for highest vs. lowest group of 0.53 (95\% CI $0.36-0.78$ ). Children born with $25(\mathrm{OH}) \mathrm{D}$ levels $<30 \mathrm{nmol} / \mathrm{L}$ seemed to be at an especially high risk of developing MS. The additional benefits of higher levels of $25(\mathrm{OH}) \mathrm{D}$ were less pronounced [41].

\section{Studies Utilizing Mendelian Randomization to Measure MS Risk}

Data on vitamin D and risk of MS have been largely based on observational studies that measure an inverse association. However, MS is identified as the primary cause of low $25(\mathrm{OH}) \mathrm{D})$ and thus cannot be excluded with these methods. Mendelian randomization (MR) analyses use genetic associations to test the effects of biomarkers, such as $25(\mathrm{OH}) \mathrm{D}$, on the risk of disease, because inherited alleles are not affected by most confounding variables or disease status $[42,43]$. Thus, the possibility of confounding or reverse causation can largely be excluded. Three recent publications made use of 
this epidemiological approach. Mokry and colleagues applied genome-wide data on genetic variants that predicted blood $25(\mathrm{OH}) \mathrm{D}$ levels from the Canadian Multicentre Osteoporosis Study to participants in the International MS Genetics Consortium study [42]. They found that a genetically determined decrease in blood 25(OH)D level predicted increased MS susceptibility. An increase of $25(\mathrm{OH}) \mathrm{D}$ levels by $50 \%$ decreased the odds of getting MS by approximately 50\% [42, 44]. Similar findings were seen from MR analyses using data from two populations, a US administrative claim database and two population-based case-control studies from Sweden [45]. The third publication, from the Network of Pediatric Multiple Sclerosis Centers, again investigated the US and Swedish datasets [43]. Genetic risk scores were used to estimate the causal association between low 25(OH)D levels and pediatric-onset MS. This data also supports independent and causal effects of decreased $25(\mathrm{OH}) \mathrm{D}$ levels on susceptibility to pediatric-onset MS [43].

\section{Studies Contradicting the Association of Vitamin D Levels with MS Risk}

Ueda and colleagues investigated the link between vitamin $\mathrm{D}$ status at birth and risk of adult-onset MS in a population-based, multicenter, case-control study in Sweden [46]. The authors analyzed stored neonatal dried blood samples of 459 MS subjects and 663 controls (matched on sex, age, and residential area). There was no association between neonatal serum $25(\mathrm{OH}) \mathrm{D}$ quintiles and risk of $\mathrm{MS}$ as adults. When the findings were adjusted for confounding factors in early life (e.g., month of birth, latitude of birth, and breastfeeding), in adult life (e.g., sun exposure, intake of vitamin D-rich dairy products, fatty fish consumption, smoking, and body mass index at 20 years of age), ancestry, MS heredity, and socioeconomic group, results were not considerably affected [46]. Whether the study provided conclusive results was the subject of debate for two primary reasons: (1) blood samples at birth were not well preserved and may have been affected by substantial degradation of $25(\mathrm{OH}) \mathrm{D}$; and (2) the range of $25(\mathrm{OH}) \mathrm{D}$ levels at birth was narrow and mostly low $($ mean $=29.7 \mathrm{nmol} / \mathrm{L}, \quad$ median $=$ 25.6 , interquartile range $=17.0-38.4 \mathrm{nmol} / \mathrm{L}$ ) [47].

Optic neuritis $(\mathrm{ON})$ is a common first symptom of MS. Pihl-Jensen and coworkers conducted a cross-sectional study to assess whether $25(\mathrm{OH}) \mathrm{D}$ levels can predict later development of $\mathrm{MS}$ in acute $\mathrm{ON}$ by evaluating the differences in mean serum $25(\mathrm{OH})$ D levels between subjects with ON $(n=164)$ and those with MS $(n=948)$ [48]. Deseasonalized serum 25(OH)D levels of the ON onset group were used for statistical analyses. The majority $(56.1 \%)$ of the patients had 25(OH)D levels below $50 \mathrm{nmol} / \mathrm{L}$ (mean $47.64 \pm 21.48 \mathrm{nmol} / \mathrm{L}$ ). There were no significant differences in 25(OH)D levels between ON subjects who developed MS and those who did not develop MS during the median follow-up time of 741 days $(P=0.279)$, indicating no statistically significant effect on the hazard of MS development. However, significant associations were found between $25(\mathrm{OH}) \mathrm{D}$ levels and elevated IgG index levels or CSF pleocytosis, both markers of inflammatory activity or risk of MS. The interpretation of the latter finding was difficult due to the risk of reverse causation. Although the role of using $25(\mathrm{OH}) \mathrm{D}$ levels as a predictor for the development of MS after acute ON could not be demonstrated, the study data do suggest that there may be a link between development of MS after acute ON. They also provide a rationale for additional research for a possible role of vitamin $\mathrm{D}$ in the early stages of MS [48].

\section{Levels of Dietary Vitamin D Intake and Risk of MS-Implications for Public Health}

Whether a daily dose of vitamin $\mathrm{D}$ or a gestational dose of vitamin D per day "keeps the MS doctor away" is not yet proven [49]. Additionally, it is not known what level of serum $25(\mathrm{OH}) \mathrm{D}$ would prevent MS in a large majority of individuals. Most studies in this review reported 25(OH)D levels below $50 \mathrm{nmol} / \mathrm{L}$ $(20 \mathrm{ng} / \mathrm{mL})$ in a significant proportion of their investigated populations, which is below the 
healthy minimum level. Indicating that establishing a target in the general population general population, pregnant women, and their offspring to achieve the minimum levels of 25(OH)D may be considered an important goal for health (i.e., $50 \mathrm{nmol} / \mathrm{L}(20 \mathrm{ng} / \mathrm{mL})$, according to IOM $[4,15]$ or $75 \mathrm{nmol} / \mathrm{L}(30 \mathrm{ng} / \mathrm{mL})$, according to the Endocrine Society) $[11,13]$.

\section{EFFECTS OF VITAMIN D STATUS AND MS DISEASE ACTIVITY}

Understanding how existing vitamin D levels and vitamin D exposure affect clinical relapses and MS lesion activity is critically important to this review. As such, the findings from larger studies investigating these effects are summarized below.

\section{Impact of Vitamin D Levels on Disease Activity in RRMS: Observational Studies}

In a prospective longitudinal study from the Netherlands, 25(OH)D was measured every 8 weeks for a mean of 1.7 years in 73 patients with RRMS [50]. Fifty-eight patients experienced a total of 139 exacerbations during the study period. Relapse risk was significantly reduced in those with medium [50-100 nmol/L $(20-40 \mathrm{ng} / \mathrm{mL})]$ and high $[>100 \mathrm{nmol} / \mathrm{L}$ $(>40 \mathrm{ng} / \mathrm{mL})]$ serum vitamin D levels (vs. $<50 \mathrm{~mol} / \mathrm{L}$ or $20 \mathrm{ng} / \mathrm{mL}$ ) compared to those with low levels [50]. For each doubling of serum vitamin D concentration from baseline of 10 , 20,30 , MS relapse risk decreased by $27 \%$. Although this suggests a beneficial effect of vitamin D on MS, it must be noted that there is also a possibility that conditions associated with MS relapse had an effect on serum vitamin D levels [50].

Incident rate ratios (RR) for relapse in relation to serum vitamin $D$ levels were measured in a retrospective study of 110 patients with pediatric-onset MS [51]. After adjusting for several factors (age, gender, race, ethnicity, disease duration, and treatment), the authors found that every $10 \mathrm{ng} / \mathrm{mL}(25 \mathrm{nmol} / \mathrm{L})$ increase in $25(\mathrm{OH}) \mathrm{D}$ level was associated with a $34 \%$ decrease in relapse risk. Similar findings were seen in a prospective cohort study from Tasmania, Australia, in a group of 145 adults with RRMS, in which 25(OH)D levels were measured twice a year for a period of 3 years [52]. For each $10 \mathrm{nmol} / \mathrm{L}$ increase in serum vitamin D level, there was an associated $12 \%$ lower risk of MS relapse. Adjustment for potential confounders, such as timing of the blood testing, did not affect the results. Most of the participants in this study $(82 \%)$ were receiving immunomodulatory therapy. The authors concluded that raising $25(\mathrm{OH}) \mathrm{D}$ levels by $50 \mathrm{nmol} / \mathrm{L}$ could decrease the hazard of a relapse by up to $50 \%$ (Fig. 4) [52].

The EPIC natural history study was a 5-year cohort study conducted at the University of California, San Francisco which sought to determine the associations between serum or plasma vitamin D levels and MRI activity in a group of 469 white, mostly non-Hispanic patients with MS or clinically isolated syndrome (CIS) [53]. Sixty-four percent received diseasemodifying therapy within the previous 12 months. Vitamin D levels increased significantly during the study, especially for those patients using supplements. Only 9\% of patients were taking vitamin $\mathrm{D}$ supplements at baseline, but $43 \%$ were taking them by year 5 . Patients who reported using vitamin D supplements had an $8.7 \mathrm{ng} / \mathrm{mL}(21.75 \mathrm{nmo} / \mathrm{L})$ higher vitamin D level, on average, compared with

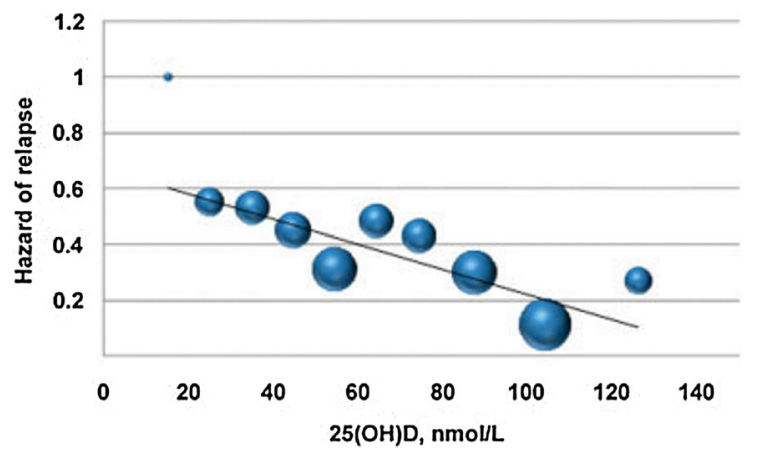

Fig. 4 Association of vitamin D and relapse risk in MS. The graph shows risk of relapse according to $25(\mathrm{OH}) \mathrm{D}$ levels, adjusted for age and month of serum measurement. Size of points is proportional to the inverse of the variance (larger bubbles represent greater precision). Reprinted with permission from Wiley Company [52] 
those who did not. Additionally, lower vitamin D levels were strongly associated with development of new T2 lesions and with contrast-enhancing lesions on brain MRI. Each additional $10 \mathrm{ng} / \mathrm{mL}(25 \mathrm{nmol} / \mathrm{L})$ increment of $25(\mathrm{OH}) \mathrm{D}$ was associated with a $15 \%$ lower risk of new T2 lesions and a 32\% lower risk of enhancing lesions (Fig. 5) [53]. Higher vitamin D levels were associated with a lower (but not statistically significantly) risk of MS relapses. Findings from this study also showed strong "withinperson" effects of vitamin D levels in individual patients with MS. The authors concluded that "individuals with CIS/RRMS with higher vitamin D levels are at much lower risk of the subsequent development of new lesions and of gadolinium $(\mathrm{Gd}+)$-enhancing lesions on brain MRI, even after accounting for potential confounding factors" [53].

More recently, Mowry and colleagues examined the association of vitamin D levels with brain volume measures and new lesions in patients with CIS $(N=65)$ [54]. The scientific rationale for these data are based on the concept that brain volume is thought to reflect neurodegeneration better than classical MRI parameters such as T2 lesion load and Gd+-enhancing lesions [54]. Each 25-nmol/L increase in $25(\mathrm{OH}) \mathrm{D}$ level was associated with 7.8 -mL higher gray matter volume $(P=0.025)$. Higher levels of $25(\mathrm{OH}) \mathrm{D}$ also were associated with the composite endpoint of $\geq 3$ new brain $\mathrm{T} 2$ lesions or $\geq 1$ relapse within 1 year $(P=0.096)$. Despite the limitations of the small sample size, these findings suggest that higher vitamin D levels in CIS may slow neurodegeneration [54].

Lower vitamin D levels also correlate with other surrogates of MS disease activity, including lower odds of remaining relapse free in MS [55], greater disability and disease severity in MS [53, 55-57], conversion from CIS to clinically definite MS (CDMS) [58], and poorer nonverbal long-term memory performance [59]. These data were largely generated by observational studies that restrict the extent to which inverse associations can be attributed specifically to vitamin D. Properly designed and conducted

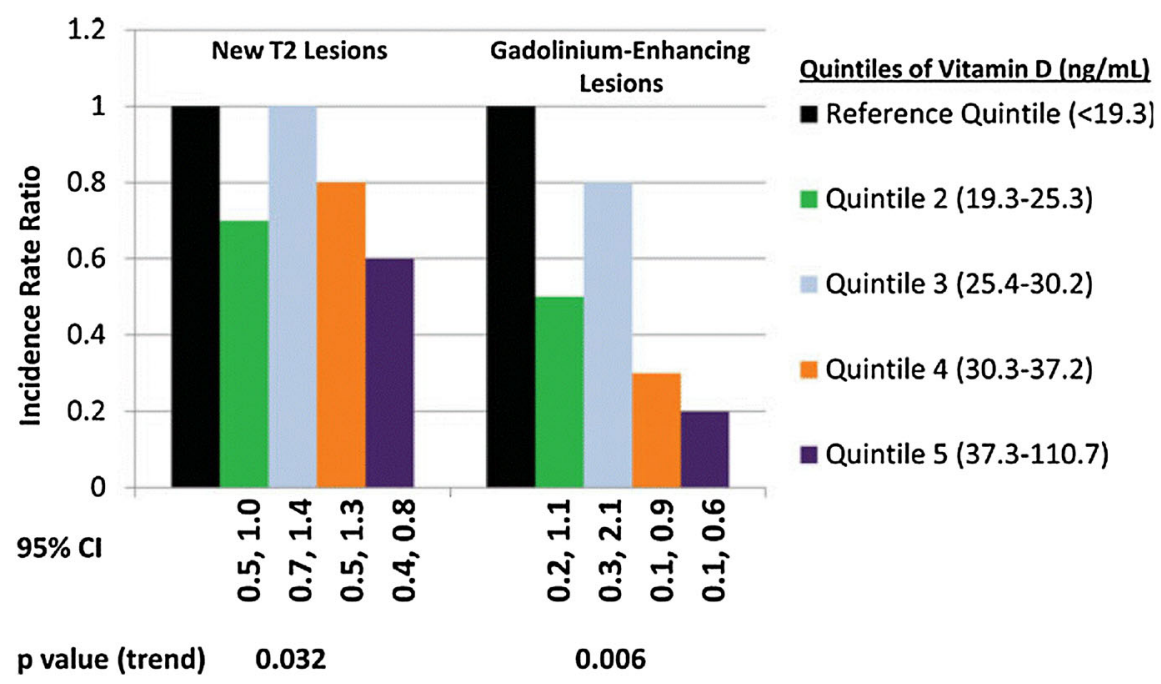

Fig. 5 Magnetic resonance imaging outcomes associated with quintiles of vitamin D in the EPIC study. EPIC is a 5-year longitudinal MS cohort study at the University of California at San Francisco, USA. Participants $(N=469)$ had clinical evaluations, brain MRI, and blood draws annually. MRI outcomes were associated with quintiles of vitamin D. In multivariate analyses, each $10 \mathrm{ng} / \mathrm{mL}$
(25 nmol/L) higher 25-hydroxyvitamin D level was associated with a $15 \%$ lower risk of a new T2 lesion (incidence rate ratio [IRR],0.85; $95 \%$ confidence interval [CI], $0.76-0.95 ; \mathrm{P}=0.004)$ and a $32 \%$ lower risk of a gadolinium-enhancing lesion (IRR, 0.68; 95\% CI, 0.53-0.87; $P+0.002)$. Reprinted with permission from Wiley Company [53] 
clinical trials are needed to further define the nature of this association.

\section{Impact of Vitamin D Levels on Disease Activity Based on Post-Hoc Analyses from BENEFIT and BEYOND}

To our knowledge, no large randomized, double-blind, controlled, prospectively phase 3 trials have been conducted to study the impact of vitamin D levels on MS activity as a primary endpoint. However, in two phase 3 studies, the BENEFIT study [60], and the BEYOND study [61] post hoc analyses were conducted to investigate this potential link.

The BENEFIT (Betaseron ${ }^{\circledR}$ in Newly Emerging Multiple Sclerosis for Initial Treatment) study was a randomized trial originally designed to evaluate the impact of early versus delayed IFNB-1b treatment in patients with CIS [62-64]. Patients with a first event suggestive of MS and a minimum of two clinically silent lesions on MRI were randomly assigned to receive interferon beta-1b (IFNB-1b) $250 \mu \mathrm{g}$ ( $n=292$; early treatment) or placebo ( $n=176$; delayed treatment) subcutaneously every other day for 2 years or until diagnosis of CDMS, in which case they could switch to IFNB-1b therapy. All patients were then eligible to enter a prospective followup phase with open-label IFNB-1b for up to 5 years after randomization. Patients and study personnel remained unaware of initial treatment allocation throughout the study up to year 5. During the observation period, regular study visits were scheduled to collect clinical and MRI data, with visits at baseline and months $3,6,9,12,18,24,36,48$, and 60 [64]. A post hoc analyses aimed to determine whether vitamin D status [serum 25(OH)D levels] would predict disease activity and prognosis up to 5 years after the first attack in early-disease CIS patients [60]. Serum samples were collected at baseline, 6, 12, and 24 months and levels of 25(OH)D were measured (by ELISA). Of the 468 patients included in BENEFIT, 465 patients had at least one $25(\mathrm{OH}) \mathrm{D}$ measurement, 417 had two or more, 396 had three or more, and 303 had all four measurements. 25(OH)D levels were seasonally adjusted to obtain an estimate of long-term $25(\mathrm{OH}) \mathrm{D}$ status. To minimize the possibility that lower $25(\mathrm{OH}) \mathrm{D}$ levels were a consequence, rather than the cause, of MS severity, the cumulative average $25(\mathrm{OH}) \mathrm{D}$ levels at 12 months were related to the outcomes between 12 and 60 months or between 24 and 60 months (thereby allowing inserting a 1-year lag between $25[\mathrm{OH}] \mathrm{D}$ measurements and the assessment of MS activity or progression) [60]. Three sets of analyses were performed: (1) continuous $50-\mathrm{nmol} / \mathrm{L}(20-\mathrm{ng} / \mathrm{mL})$ increments to determine the overall linear trend; (2) quintiles to explore the dose response; and (3) categorical analysis using $\geq 50 \mathrm{nmol} / \mathrm{L}$ versus $<50 \mathrm{nmol} / \mathrm{L}$ (20 ng/mL) [60].

Findings indicated that patient characteristics affected vitamin D levels. Those with higher (seasonally adjusted) 25(OH)D levels tended to be younger and to have a lower body mass index (BMI), a lower number of T2 lesions, and a higher brain volume at the CIS stage, but otherwise were similar to patients with lower levels of 25(OH)D [60].

Over the 5-year follow-up period, $81.3 \%$ (377 patients) converted to MS according to the McDonald 2001 criteria that include MRI lesions [65] and 46.6\% (216 patients) converted to CDMS based on exacerbations or progression alone. The hazard of conversion decreased with increasing serum $25(\mathrm{OH}) \mathrm{D}$ and mean serum $25(\mathrm{OH}) \mathrm{D}$ levels at 12 months predicted subsequent conversions to McDonald MS $(P=0.02)$ and CDMS $(P=0.05)$ [60].

An increasing serum $25(\mathrm{OH}) \mathrm{D}$ level was associated with a decreasing rate of new active lesions on MRI; this effect was particularly strong in patients with both 6- and 12-month serum 25(OH)D measurements. A $50 \mathrm{nmol} / \mathrm{L}$ $(20 \mathrm{ng} / \mathrm{mL})$ increment in average serum 25(OH)D levels within the first 12 months predicted a $57 \%$ lower rate of new active lesions (RR, 95\% CI: 0.43 (0.26-0.70), $P<0.001)$ and a $57 \%$ lower relapse rate (RR $(95 \%$ CI): 0.43 $(0.20-0.92, P=0.03)$. In evaluating the potential progression of MS on MRI, higher levels of serum $25(\mathrm{OH}) \mathrm{D}$ were associated with less $\mathrm{T} 2$ lesion volume accumulation over time. For a $50 \mathrm{nmol} / \mathrm{L}$ increase in serum $25(\mathrm{OH}) \mathrm{D}$, the relative decrease in T2 lesion volume was $20 \%$ per year $(P<0.001)$. Restricting results to patients 
with both 6-month and 12-month serum $25(\mathrm{OH}) \mathrm{D}$ measures, tended to strengthen results [60].

The dichotomous analysis of serum $25(\mathrm{OH}) \mathrm{D}$ levels ( $<50$ vs. $\geq 50 \mathrm{nmol} / \mathrm{L}$ ) is shown in Fig. 6 [60]. For instance, the percentage loss of brain volume over time was lower in patients with $25(\mathrm{OH}) \mathrm{D}$ levels $\geq 50 \mathrm{nmol} / \mathrm{L}$ at the 12 -month time point compared with those with serum

a

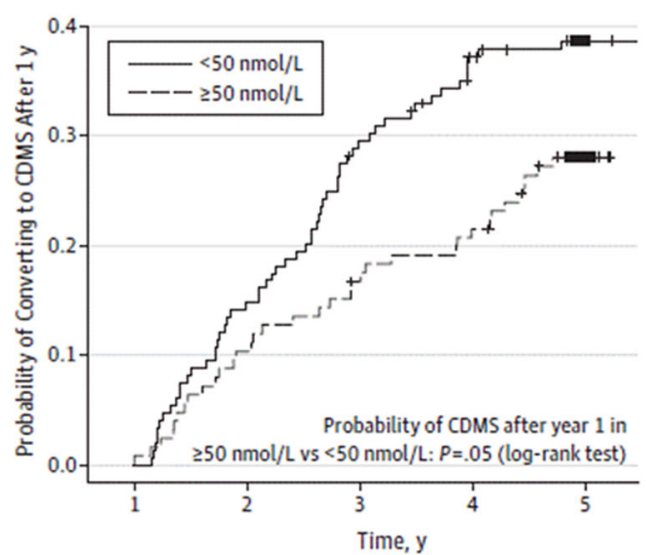

No. $\begin{array}{rrrrrr}\text { No. } & & & & \\ (<50 \mathrm{nmol} / \mathrm{L}) & 150 & 128 & 106 & 95 & 85 \\ (\geq 50 \mathrm{nmol} / \mathrm{L}) & 127 & 114 & 106 & 100 & 88\end{array}$

C

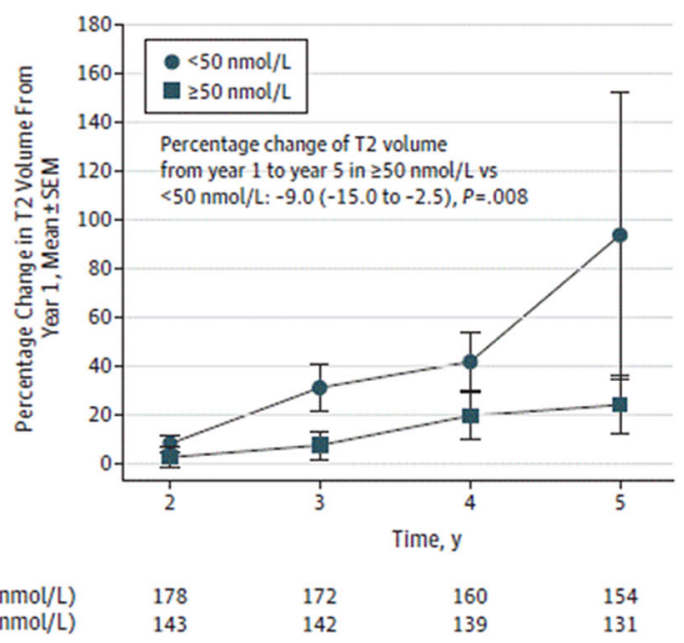

Fig. 6 Multiple sclerosis outcomes according to dichotomous serum 25(OH)D levels. Analyses are based on patients with averaged 6- and 12-month measurements of $25(\mathrm{OH}) \mathrm{D}$. Group comparisons are adjusted for age, sex, treatment, time of follow-up, and T2 lesion score at baseline. The graphs show the probability of conversion to CDMS after 12 months (a); the cumulative number of
25(OH)D levels $<50 \mathrm{nmol} / \mathrm{L} \quad(P=0.005)$. Although a $50 \mathrm{nmol} / \mathrm{L}$ increase in $25(\mathrm{OH}) \mathrm{D}$ levels did not reach significance for a reduction in the average expanded disability status scale (EDSS) score $(P=0.11)$, patients with serum $25(\mathrm{OH}) \mathrm{D}$ levels $\geq 50 \mathrm{nmol} / \mathrm{L}$ had a significantly lower annualized change in EDSS score compared with those patients with serum $25(\mathrm{OH}) \mathrm{D}$ levels $<50 \mathrm{nmol} / \mathrm{L}(P=0.004)$ while on IFN-b-
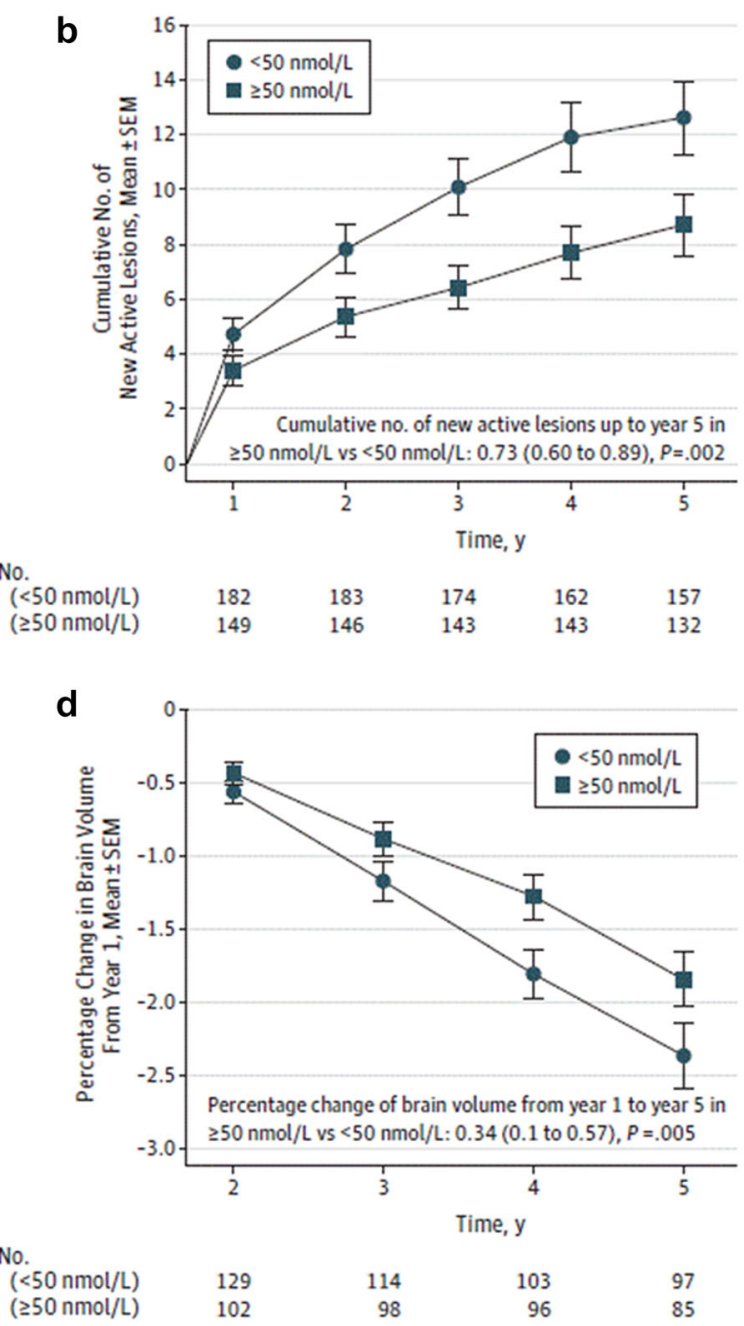

new active lesions on brain MRI (b); the percentage change in T2 lesion volume from year 1 to year 5 on brain MRI (c); and the percentage change in brain volume from year 1 to year $5(\mathrm{~d})$. The error bars indicate the standard error of the mean (SEM). Reproduced with permission from [60]. Copyright(C2014 American Medical Association. All rights reserved 
Table 2 Comparison of clinical and MRI outcomes in patients with plasma $25(\mathrm{OH}) \mathrm{D}$ levels $<50 \mathrm{nmol} / \mathrm{L}$ versus $\geq 50 \mathrm{nmol} / \mathrm{L}$ in all

Reproduced with permission from [60]. Copyright@2014 American patients and those with early or delayed start of interferon beta- $1 \mathrm{~b}$.

Medical Association. All rights reserved

\begin{tabular}{lccc}
\hline & All patients & Early treatment & Delayed treatment \\
\hline Probability of conversion CDMS up to & $0.65(0.42-0.99)$, & $0.48(0.28-0.83)$, & $1.22(0.59-2.5)$, \\
year 5, RR (95\% CI) & $P=0.05$ & $P=0.008$ & $P=0.6$ \\
Cumulative number of new lesions up to & $0.73(0.60-0.90)$, & $0.70(0.55-0.90)$, & $0.71(0.52-0.97)$, \\
year 5, RR (95\% CI) & $P=0.002$ & $P=0.005$ & $P=0.03$ \\
Percent change in T2 volume from year & $-8.99(-15.1$ & $-11.0(-19.0$ & $-8.84(-17.14$ to \\
1-5, \% (95\% CI) & to -2.5$), P=0.008$ & to -2.2$), P=0.02$ & $0.29), P=0.06$ \\
Percent change in brain volume from year & $0.34(0.10-0.57)$, & $0.43(0.14-0.72)$, & $0.17(-0.24$ to 0.58$)$, \\
$1-5, \%$ (95\% CI) & $P=0.005$ & $P=0.004$ & $P=0.4$ \\
\hline
\end{tabular}

All data were adjusted for age, sex, treatment, time of follow-up, and T2 lesion score at baseline $C D M S$ Clinically definite multiple sclerosis, $R R$ rate ratio

${ }^{a}$ Includes new T2 lesions, new Gd + -enhancing lesions, and enlarging T2 lesions

1b. Across all analyses, associations were generally stronger for MRI than for clinical outcomes. Nevertheless, "the latter were still remarkable considering the overall low rate of relapses ( 0.2 per year) and small EDSS score change (median change, 0.0) in BENEFIT" [60].

Strengths of the BENEFIT study included (1) its longitudinal design, (2) the exclusive recruitment of patients at the CIS stage, (3) the use of repeated serum $25(\mathrm{OH}) \mathrm{D}$ measurements, (4) the large number of patients, (5) standardized treatment (e.g., early vs. late IFNB-1b), and (6) rigorous clinical and MRI assessment of all patients during a 5-year period. Limitations of the study included (1) the fact that most patients were eventually treated with IFNB-1b and some crossed over during the 2 years of the study, and (2) while a clear dose response was observed for the most sensitive MRI outcomes, the effects did not reach a plateau level, and, therefore, serum $25(\mathrm{OH}) \mathrm{D}$ levels greater than the median $69 \mathrm{nmol} / \mathrm{L}$ could have had a greater effect. According to the authors, a low 25(OH)D level early in the disease course is a strong risk factor for long-term MS activity and progression in patients with early MS who were treated with IFNB-1b [60].

The BENEFIT cohort had an early treatment group and a delayed treatment group. The associations of $25(\mathrm{OH}) \mathrm{D}$ levels and MS activity were more pronounced for patients in the early treatment group than for those in the delayed treatment group (Table 2 [60] and Fig. 7 [66]), although a test for interaction between $25(\mathrm{OH}) \mathrm{D}$ levels and treatment assignment was significant only for the time to CDMS $(P=0.04)$ [62]. These results suggest that early treatment with IFNB-1b may have an additive effect along with $25(\mathrm{OH}) \mathrm{D}$ to reduce disease severity and progression in both clinical and imaging outcomes.

To explore the mechanistic rationale for the potential additive effects of $25(\mathrm{OH}) \mathrm{D}$ levels and early IFNB-1b treatment, Munger and colleagues conducted a global gene expression analysis in which expression profiles were measured at various time points among participants in the BENEFIT clinical trial [67]. The relationship between genes or gene sets expressed in association with $25(\mathrm{OH}) \mathrm{D}$ and those associated with MS activity was examined. The numbers of $\mathrm{Gd}+$-enhancing lesions served as a marker of disease activity. A $50 \mathrm{nmol} / \mathrm{L}$ increase in serum 25(OH) levels reduced the $\mathrm{Gd}+$ lesion count by $55 \%$. Adjusting for gender, age, treatment, and treatment $-25(\mathrm{OH}) \mathrm{D}$ interaction did not alter the significance of the findings. Gene expression in whole blood was studied in 295 individuals, evaluating approximately 19,000 genes. 


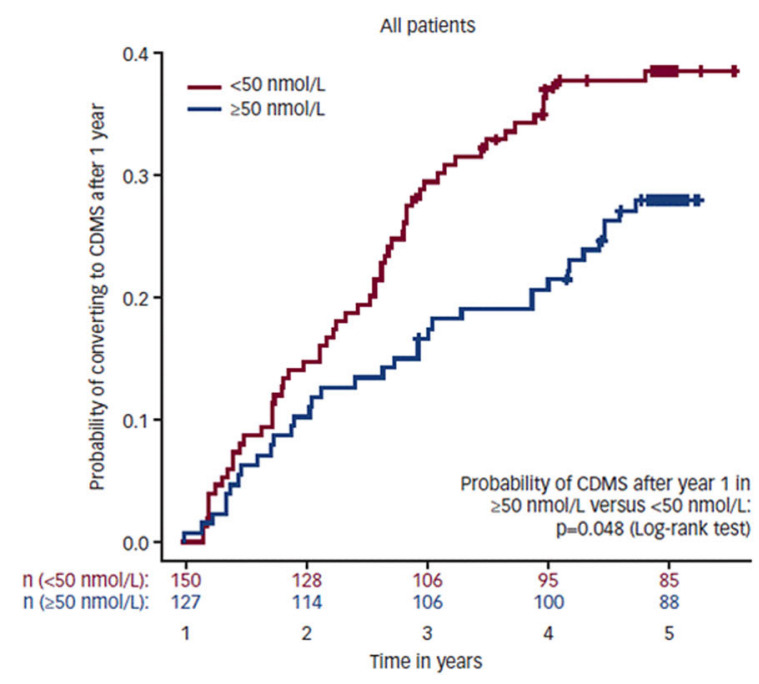

Fig. 7 Data from the Vitamin D analysis of the BENEFIT trial. Comparison of probability of conversion to CDMS in patients with plasma $25(\mathrm{OH}) \mathrm{D}<50 \mathrm{nmol} / \mathrm{L}$

Reduced Gd+ lesion count was significantly associated with increased expression of $25(\mathrm{OH}) \mathrm{D}$-related genes, an effect that was independent of IFNB-1b treatment. This effect was also noticed when looking at single genes that were associated with regulation of $25(\mathrm{OH}) \mathrm{D}$ levels. The authors hypothesized that there was an additive effect of $25(\mathrm{OH}) \mathrm{D}$ and IFNB-1bin reducing Gd+ lesion counts [67].

The second data set from randomized, double-blind, phase 3 trials in MS was derived from the BEYOND (Betaseron ${ }^{\circledR}$ Efficacy Yielding Outcomes of a New Dose) study [61]. Compared with the BENEFIT study, the BEYOND study included patients with established MS (vs. patients with CIS) and was shorter in duration ( 2 vs. 5 years). It also included considerably more patients (1482 vs. 465 ) and was conducted in different geographical regions (North America, Western and Eastern Europe, Southern Hemisphere vs. Europe and Canada).

BEYOND was a large, phase 3, prospective, multicenter, blinded, randomized clinical trial. Patients were monitored for at least 2 years. Clinical visits were scheduled every 3 months, and an MRI was performed at baseline and annually thereafter. A post hoc analysis assessed 25( $(\mathrm{OH}) \mathrm{D}$ levels and the subsequent MS disease

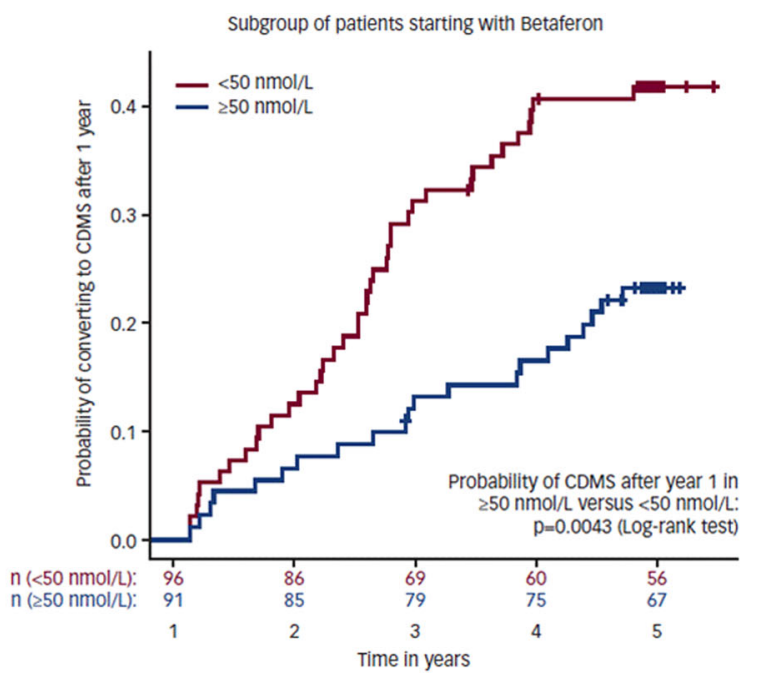

versus $\geq 50 \mathrm{nmol} / \mathrm{L}$ in all patients and those with early or delayed start of interferon beta-1b. Reproduced with permission from [66]

course and disease progression as characterized by MRI and clinical endpoints [58]. Eligible patients for the vitamin $D$ analyses included 1482 participants randomized to receive 250 , or $500 \mu \mathrm{g}$ of IFNB-1b with at least two measurements of $25(\mathrm{OH}) \mathrm{D}$ obtained 6 months apart. Serum 25(OH)D measurements were performed at baseline, 6 , and 12 months.

In longitudinal analyses, $25(\mathrm{OH}) \mathrm{D}$ was inversely correlated with the cumulative number of active lesions between baseline and the last MRI (average follow-up time, 2 years). A $50-\mathrm{nmol} / \mathrm{L}$ higher level of serum $25(\mathrm{OH}) \mathrm{D}$ was associated with a $31 \%$ lower rate of new lesions [relative rate (RR), 0.69 ; 95\% CI, 0.55-0.86; $P=0.001]$. This inverse association was also strong and significant in analyses restricted to patients with $25(\mathrm{OH}) \mathrm{D}$ levels $>50 \mathrm{nmol} / \mathrm{L}(\mathrm{RR}$, $0.62 ; 95 \% \mathrm{CI}, 0.46-0.84 ; P=0.002$ ) and was consistent in each of the four geographic regions (Fig. 8) [61]. The lowest rate of new lesions was observed among patients with 25(OH)D levels $>100 \mathrm{nmol} / \mathrm{L}$ (RR, 0.53; 95\% CI, $0.37-0.78 ; P=0.002)$. No significant associations were found between 25(OH)D levels and change in brain volume, relapse rates, or EDSS scores [61]. Strengths of this study include the large number of participants, the regionally 


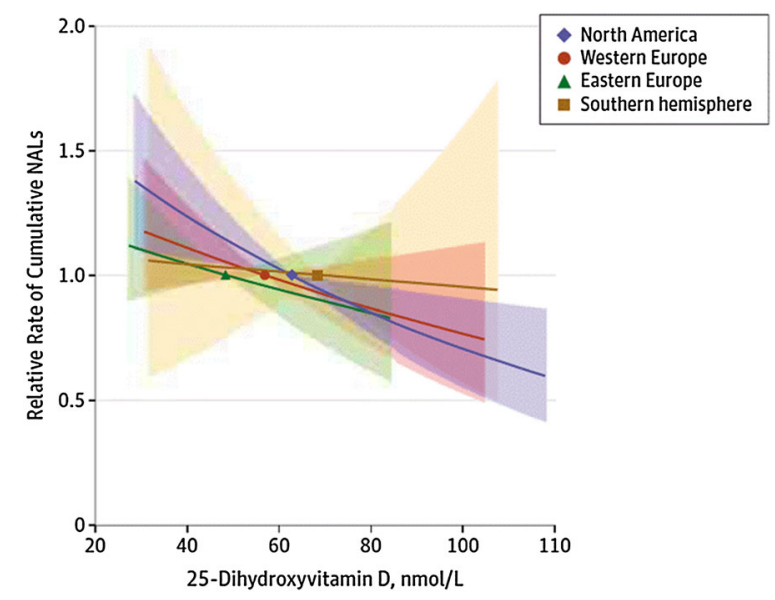

Fig. 8 The relative rate of cumulative new active lesions (NALs) vs. average of baseline, 6-month, and 12-month $25[\mathrm{OH}] \mathrm{D}$ levels stratified by geographic region. The solid lines and shaded regions represent the relative rate ratios of cumulative NALs for changes in $25(\mathrm{OH}) \mathrm{D}$ relative to the median level and the corresponding 95\% CIs, respectively. Analyses were adjusted for age, sex, randomization status, baseline EDSS score, and disease duration. Models assume a linear association between the logarithm of the rate of cumulative NALs and serum 25(OH)D. Analyses using cubic splines revealed no significant deviation from linearity. (To convert 25[OH]D values to $\mathrm{ng} / \mathrm{mL}$, divide by 2.496). Reproduced with permission from [61]. Copyright $(2015$ American Medical Association. All rights reserved

diverse population with varying baseline characteristics, and the repeated measurements of $25(\mathrm{OH}) \mathrm{D}$, which helped characterize patients' long-term vitamin D status. The relatively short follow-up is the most important limitation of this study. This limited follow-up may explain the lack of association between serum 25(OH)D levels and measures of brain atrophy or clinical endpoints, both of which were modified by $25(\mathrm{OH}) \mathrm{D}$ in the longer BENEFIT study $[60,61]$. Regarding targeted vitamin D levels, the authors stated: "Our observation of the lowest level of MS activity among patients with serum $25(\mathrm{OH}) \mathrm{D}$ levels above $100.0 \mathrm{nmol} / \mathrm{L}$ [ $40 \mathrm{ng} / \mathrm{mL}$ ] is consistent with the results of a previous investigation in the US [50], and suggests that the 25(OH)D levels in most patients with MS who are not receiving supplemental vitamin $\mathrm{D}$ may be suboptimal" [53].

\section{Effects of Disease-Modifying Therapies on Vitamin D Levels in MS Patients}

MS disease activity may be additively affected by vitamin $\mathrm{D}$ and IFNB-1b [60]. This hypothesis is supported by investigations from the same researchers suggesting that processes regulated and triggered by $25(\mathrm{OH}) \mathrm{D}$ may be additively enhanced by IFNB-1b [67], and independently by observations from Stewart and colleagues from the Menzies Research Institute in Tasmania [68]. In an observational cohort study, conducted in 178 patients with MS, vitamin D levels were measured every 6 months over an average of 2.2 years. Patients who took an interferon had significantly higher $25(\mathrm{OH}) \mathrm{D}$ levels than those who did not $(P<0.001)$. Each $10-\mathrm{nmol} / \mathrm{L}$ increase in serum vitamin $\mathrm{D}$ was associated with a $10 \%$ lower relapse rate. Interestingly, interferon treatment was protective only against relapse among persons with higher vitamin D levels. Among those with insufficient vitamin $\mathrm{D}$, there was an increased risk of relapse despite interferon treatment. The investigators hypothesized that treatment with IFNB may increase serum vitamin $D$ levels through enhanced responsiveness to sun exposure and recommended that persons being treated with IFNB should have vitamin D status monitored and maintained in the sufficiency range [68]. Also, noteworthy from these data, this group did not find similar associations for glatiramer acetate (GA) therapy and vitamin D.

The notion of complementary or even synergistic effects of IFNB and vitamin D is further supported by observations from Rotstein and coworkers based on the CLIMB (Comprehensive Longitudinal Investigation of MS at Brigham and Women's Hospital) cohort [69]. The CLIMB cohort is a prospective cohort study that began enrolling patients in 2000. The objective of the study was to determine whether $25(\mathrm{OH}) \mathrm{D}$ levels predicted new disease activity in MS patients treated with IFN- $\beta(n=96)$ or GA $(n=151)$. Separately, due to different selection criteria, a similar analysis was conducted for patients treated with fingolimod (FTY, $n=77$ ). Serum $25(\mathrm{OH}) \mathrm{D}$ concentration was adjusted for season, and patients were divided into subgroups by $25(\mathrm{OH}) \mathrm{D}$ tertile. The primary study endpoint 
was 'time to first inflammatory event', defined as a combination of either first relapse or first $\mathrm{Gd}+$ lesion, using a Cox model adjusted for age, sex, and disease duration. The results demonstrated higher $25(\mathrm{OH}) \mathrm{D}$ levels associated with a longer time to the combined first event in the IFNB subgroup [hazard ratio $(\mathrm{HR})_{\mathrm{IFNB}}=0.58$; $\left.P_{\mathrm{IFNB}}=0.012\right]$, but not in GA-treated participants $\left(\mathrm{HR}_{\mathrm{GA}}=0.89 ; \quad P_{\mathrm{GA}}=0.50\right)$. For $\mathrm{Gd}+$ lesions alone, there was a significant association observed in GA and IFNB subgroups, although the effect was more pronounced with IFNB $\left(\mathrm{HR}_{\mathrm{GA}}=0.57 ; P_{\mathrm{GA}}=0.039\right.$ vs. $\mathrm{HR}_{\mathrm{IFNB}}=0.41$; $\left.P_{\mathrm{IFNB}}=0.022\right)$. No significant associations were found for relapses. There were some sampling difficulties in this cohort and, therefore, the results need to be interpreted with certain caution. For FTY, due to the mandated first-dose observation, samples were available for all patients. Higher $25(\mathrm{OH}) \mathrm{D}$ was associated with a longer time to the first event $\left(\mathrm{HR}_{\mathrm{FTY}}=0.48\right.$; $\left.P_{\mathrm{FTY}}=0.016\right)$ and with relapses $\left(\mathrm{HR}_{\mathrm{FTY}}=0.50\right.$; $\left.P_{\text {FTY }}=0.046\right)$, but not with $\mathrm{Gd}+$ lesions [69]. The large, prospective cohort and the prolonged follow-up times were strengths of this study, as well as the availability of two $25(\mathrm{OH}) \mathrm{D}$ measurements for the majority of patients. However, more regular $25(\mathrm{OH}) \mathrm{D}$ measurements would have been ideal and offered greater insights into study conclusions [69].

\section{Studies Contradicting the Association of Vitamin D Levels with Disease Activity}

Contradictory to the aforementioned information are findings reported by researchers from Norway [70]. In this small prospective cohort study, 88 patients with RRMS were followed with regular MRI and 25(OH)D measurements during 6 months before and up to 18 months after initiation of IFNB. During the pre-IFNB treatment phase, higher levels of $25(\mathrm{OH}) \mathrm{D}$ were associated with reduced MRI activity; each $10-\mathrm{nmol} / \mathrm{L}$ increase in $25(\mathrm{OH}) \mathrm{D}$ was associated with $12.7 \%(P=0.037)$ lower odds for new T1 Gd + lesions, $11.7 \%(P=0.044)$ lower odds for new T2 lesions, and $14.1 \%(P=0.024)$ lower odds for combined unique activity. However, there was no association between $25(\mathrm{OH}) \mathrm{D}$ and disease activity after initiation of IFNB. With clinical measures, neither the occurrence of relapses nor EDSS progression was associated with $25(\mathrm{OH}) \mathrm{D}$ levels during both study phases. Strengths of the study were the prospective design and the frequent MRI and 25(OH)D assessments during the observation period. Limitations were the relatively short time on IFNB and the small number of participants, as well as the minimal $4 \mathrm{nmol} / \mathrm{L}$ increase in serum vitamin D levels following vitamin D supplementation. In the discussion of the study results, the authors expressed their surprise about the lack of an association between $25(\mathrm{OH}) \mathrm{D}$ levels and MRI after initiation of IFNB, "as there is no evidence suggesting that the immunomodulatory effects of vitamin $D$ are counteracted by IFNB or vice versa. A reasonable explanation is that IFNB reduced radiologic disease activity, leaving relatively little left to be reduced" by vitamin D [70].

\section{THE ROLE OF SUPPLEMENTAL VITAMIN D IN MS}

When reviewing available data discussing the effects of vitamin D and MS, of key interest is whether vitamin D supplementation can favorably alter the course of MS. Unfortunately, current evidence does not offer consensus to answer this question. Studies with vitamin D alone or with vitamin $\mathrm{D}$ as an add-on to a disease-modifying therapy are conflicting [22, 71-81]. Although these studies are generally small, largely uncontrolled, and used highly variable doses of vitamin $\mathrm{D}$, it can be noted that there are initial promising data arguing for vitamin D supplementation in patients with MS [22, 75-81]. Furthermore, recent investigations with immunological response markers suggest that vitamin D supplementation in patients with MS exhibits in vivo pleiotropic immunomodulatory effects in MS [82], and lacking evidence of a treatment effect does not necessarily demonstrate proof of no effect. 


\section{Studies Supporting the Benefit of Supplemental Vitamin D}

Researchers from Finland conducted a 1-year, randomized, double-blind, placebo-controlled trial with vitamin D3 as an add-on treatment to IFNB-1b in patients with MS. Thirty-four patients were randomly assigned to the treatment group (vitamin D, 20,000 IU/week vitamin D3 (cholecalciferol), and IFNB-1b) and 32 to the control group (placebo and IFNB-1b) [75]. The primary outcome measure was an MRI T2 burden of disease (BOD), which tended to increase more in the placebo group (median change of $287 \mathrm{~mm}^{3}$ ) than in the vitamin D group (median change of $83 \mathrm{~mm}^{3}$ ); however, the difference was not statistically significant $(P=0.105)$ (Fig. 9) [75]. Results for other MRI outcomes were mixed. The number of $\mathrm{T} 1 \mathrm{Gd}+$ lesions decreased in both groups $(P=0.002)$, but the change was significantly higher in the vitamin $\mathrm{D}$ group $(P=0.04)$. New/enlarging T2 lesions at the 12-month point trended higher in the placebo group, but the differences were not statistically significant $(P=0.286)$. The percentage of patients with MRI activity (12-month time point) trended lower in the vitamin $\mathrm{D}$

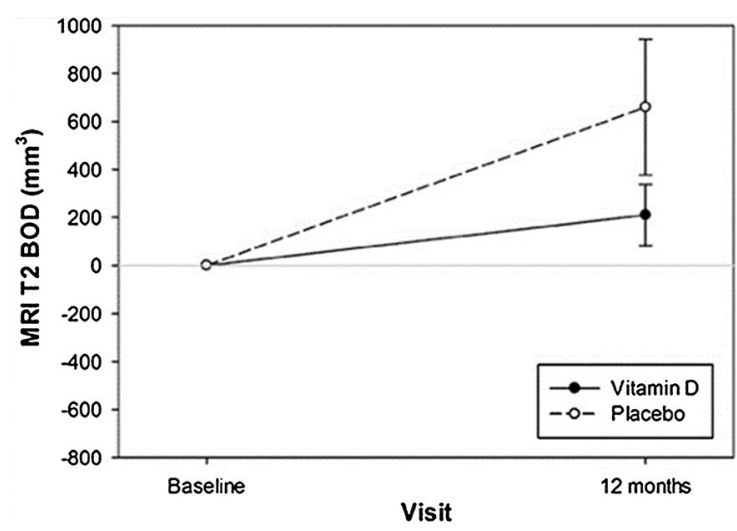

Fig. 9 Change in MRI T2 burden of disease (BOD) from baseline to month 12 in the vitamin D-treated and placebo-treated patients. Data are mean \pm standard error of 34 patients in the vitamin D group and 32 patients in the placebo group at baseline and 32 in the vitamin D group and 30 in the placebo group at 12 months. The $P$ value for the difference between vitamin $\mathrm{D}$ and placebo is 0.105 (trend). Reproduced from [75], with permission from BMJ Publishing Group Ltd group, but these differences also did not reach significance $(P=0.322)$. While there was no significant difference in annual relapse rate demonstrated between groups, there was a tendency toward reduced disability accumulation as measured by EDSS $(P=0.071)$ and toward improved timed tandem walk $(P=0.076)$. There were no significant differences in adverse events between the groups. The authors concluded that larger randomized, controlled trials with more than 1 year of follow-up are warranted to confirm the promising MRI results and to fully address clinical outcomes [75].

A study by Burton and colleagues introduced earlier in this manuscript in the context of the safety profile of higher doses of vitamin D supplementation also offers insight into the role of vitamin $\mathrm{D}$ supplementation and the disease course of MS [22]. In this open-label, controlled trial, patients were randomized to a vitamin $\mathrm{D}$ treatment group $(n=25$, escalation protocol 4000-40,000 IU/day, mean 14,000 IU/day) or to a control group $(n=24$, received vitamin D3 $4000 \mathrm{IU} /$ day if desired). Despite the high doses of vitamin D, no significant adverse events occurred during the 52-week study period. The annualized relapse rate during the trial year was lower in the treatment group than in the control group (0.26 vs. $0.45 ; P=0.09)$, and more patients in the treatment group remained relapse free. Additionally, the treated patients reported a persistent reduction in T-cell proliferation compared with controls, and treatment group patients appeared to have fewer relapse events and a persistent reduction in T-cell proliferation compared to controls. Study limitations included the use of supplementation or other agents in the control group, the small sample-size, and thus the limited power [22].

The Danish Multiple Sclerosis Center prospectively gathered data in a cohort of 170 natalizumab-treated patients during winter 2009-2010 (baseline) with follow-up during the subsequent winter [78]. Patients with insufficient serum 25(OH)D levels (selected cut-off $50 \mathrm{nmol} / \mathrm{L}$ ) at baseline were advised to take Vitamin D supplements according to Danish recommendations: $2000 \mathrm{IU}$ for patients with levels between 25 and $50 \mathrm{nmol} / \mathrm{L}, 3000 \mathrm{IU}$ for 
those with levels between 25 and $12.5 \mathrm{nmol} / \mathrm{L}$ and $4000 \mathrm{IU}$ for those with levels below $12.5 \mathrm{nmol} / \mathrm{L} .134$ patients were included in the clinical data set. Of the 134 patients, 43 had taken vitamin D supplements due to vitamin D insufficiency (mean 25(OH)D levels: $34 \mathrm{nmol} / \mathrm{L}$ ). Their levels increased significantly by $32.6 \mathrm{nmol} / \mathrm{L} \quad(95 \% \quad \mathrm{CI}: \quad 24.4-40.8 \mathrm{nmol} / \mathrm{L}$, $P<0.0001)$ from baseline to follow-up. Moreover, a significant inverse relationship with the annualized relapse rate (ARR) was found: for each nmol/l increase in $25(\mathrm{OH}) \mathrm{D}$, a $0.014(95 \%$ $\mathrm{CI}-0.026$ to -0.003$)$ decrease in ARR was observed $(P=0.02)$. Overall, the data suggest that correcting vitamin D insufficiency by the means of vitamin D supplements in patients with MS may be beneficial [78].

Darwish and colleagues looked into the cognitive effects of vitamin D supplementation of patients with MS on IFNB [79]. At baseline, patients were stratified into a vitamin D-deficient group $(25(\mathrm{OH}) \mathrm{D}$ levels $<25 \mathrm{ng} / \mathrm{mL}$ or $62.5 \mathrm{nmol} / \mathrm{L}, N=39)$ and a vitamin D-sufficient group $(25(\mathrm{OH}) \mathrm{D}$ levels $>35 \mathrm{ng} / \mathrm{mL}$ or $87.5 \mathrm{nmol} / \mathrm{L})$. "Deficient" patients received 10,000 IU vitamin D3 daily for 3 months and reported a significant increase of $25(\mathrm{OH}) \mathrm{D}$ levels to $49.0 \pm 14.6 \mathrm{ng} / \mathrm{mL} \quad(122.5 \pm 36.5 \mathrm{nmol} / \mathrm{L})$. Additionally, after 3 months these "deficient" patients scored better on the Brief Visuospatial Memory test delayed recall (BVMT-DR, $P=0.02)$ and the montreal cognitive assessment (MoCA, $P=0.006$ ), but not on the symbol digit modalities test (SDMT) and Stroop. The authors concluded that the lack of significant change on the SDMR and Stroop testing was due to the short disease duration and the propensity for study participants to perform within normal ranges for these tests.

Alternatively, "sufficient" patients continued their usual treatment that may have included vitamin D3 supplementation at various dosages. These patients reported $25(\mathrm{OH}) \mathrm{D}$ levels at $64.2 \pm 18.7 \mathrm{ng} / \mathrm{mL} \quad(160.5 \pm 46.8 \mathrm{nmol} / \mathrm{L}) \quad$ at study end. Sufficient $25(\mathrm{OH}) \mathrm{D}$ levels predicted better cognitive performance on the BVMT-DR at baseline and 3 months after adjusting for all measured confounding variables. Study limitations included a small study population $(N=88)$, short study duration (3 months), and a quarter of the patients not returning to the month 3 visit. The authors also described not allowing true control for other sources of vitamin $\mathrm{D}$ as other possible confounders, such as sun exposure and dietary vitamin D [79].

Only available in abstract format are the results of two studies which evaluated the benefits and risks associated with high-dose vitamin D supplementation in patients treated with IFNB-1a. Although both failed to demonstrate an effect on clinical parameters, their MRI results demonstrated positive results.

- SOLAR is a randomized, double-blind, placebo-controlled, multicenter, phase 2 study. Two hundred and twenty-nine patients with a $25(\mathrm{OH}) \mathrm{D}$ serum level below $150 \mathrm{nmol} / \mathrm{L}$ were randomly assigned to cholecalciferol at a dose of 14,000 IU per day or placebo [80]. All patients received subcutaneous IFNB-1a. After recruitment delays, the study design was adjusted and the percentage of patients with "disease activity free" status (defined as no relapses, no EDSS progression, and no new Gd+ or T2 MRI lesions) at week 48 were introduced as a new primary endpoint. This endpoint was not met $(37.2 \%$ for cholecalciferol group vs. $35.3 \%$ for placebo group, $P=0.912$ ). Likewise, no differences between groups for other clinical parameters such as ARR or EDSS were found. However, results regarding the MRI parameters were promising with a significant $32 \%$ reduction in the number of new, combined, unique active lesions in the cholecalciferol group $(P=0.005)$. Furthermore, there was a trend toward more cholecalciferol recipients being free from new T1 hypointense lesions, which became significant in those aged 18-30 years. The short duration of the trial (48 weeks) and the relatively small sample size (229 patients) may have led to the lack of significance of the clinical outcomes. For comparisons, most randomized trials of new MS drugs recruited over 800 patients to be able to demonstrate a significant effect vs. placebo. Despite the large sizes, some were not able to show a significant effect on disability progression (e.g. CONFIRM study [83] TRANSFORMS [84]). Additionally, these data are not placebo-controlled, but rather 
an active comparator. Also, the power analysis is not designed to assess a minor effect and would require $>10,000$ patients.

- Likewise, the second study was a randomized, placebo-controlled, phase 2 study [81]. One hundred and twenty-nine patients $(N=129)$ were randomly assigned to receive $100,000 \mathrm{IU}$ of cholecalciferol twice monthly (equivalent to a daily dose of $7143 \mathrm{IU}$ ) in addition to IFNB-1a over a 24-month period. Again, significant effects in favor of vitamin D supplementation were found for selected MRI parameters such as new or enlarged weighted T1 and T2 lesion, but no effect was found for clinical parameters [81].

A preliminary study from Iran conducted by Etemadifar and colleagues assessed the safety and efficacy of high-dose vitamin D supplementation during pregnancy in women with MS [76]. Fifteen pregnant women with confirmed MS and with serum 25(OH)D levels $<50 \mathrm{nmol} / \mathrm{L}(20 \mathrm{ng} / \mathrm{mL})$ were randomly allocated to received 50,000 IU/week (daily dose of $7143 \mathrm{IU}$ ) vitamin D3 or routine care from 12 to 16 weeks of gestation until delivery. $25(\mathrm{OH}) \mathrm{D}$ levels increased significantly and no significant adverse events occurred. The women in the vitamin $D$ group had significantly fewer relapses during pregnancy ( 0 vs. $5 ; P<0.05$ ), a tendency for fewer relapses up to 6 months after pregnancy ( 0 vs. 4 ; statistically nonsignificant), and a more stable EDSS than those without supplementation. The authors advocated for adding high-dose vitamin D3 supplementation during pregnancy to the routine care of women with MS. Study limitations included a small sample size, and conclusions are limited by the loss to follow-up of 37 out of 52 of the original baseline cohort [76].

The role of vitamin $\mathrm{D}$ supplementation in patients with MS was also evaluated by Jelinek and colleagues, with the authors taking a very different epidemiological approach [77]. This was an internet survey among 2301 patients with MS who self-reported data on geographical location, intentional sun exposure for health, supplementation with vitamin $\mathrm{D}$, and other lifestyle variables, as well as self-reported doctor-diagnosed relapse rates and disability (Patient Determined Disease Steps). Survey participants were asked to respond to a healthrelated quality-of-life (HRQoL) questionnaire. Bivariate and multivariate analyses were used for comparisons, including multiple linear regression modeling. Nearly two thirds of respondents $(64.6 \%)$ lived in the Northern Hemisphere, mostly in developed countries. Most (82.3\%) were female, with a median age of 45 years (interquartile range [IQR]: $38-53$ years) and a median time since diagnosis of 6 years (IQR: 3-12 years), with the majority (61.6\%) having RRMS. More than $80 \%$ of the patients indicated that they took vitamin D supplements, mostly between 2000 and 5000 IU daily (Table 3) [77], and $67 \%$ reported intentional sun exposure to raise vitamin D levels.

Unadjusted regression modeling incorporating deliberate sun exposure, latitude, and vitamin D supplementation showed strong associations between sun exposure and HRQoL. However, the effect disappeared when controlling for age, disability, physical activity, and fish consumption. In contrast, the associations between supplementation of vitamin $\mathrm{D}$ and HRQoL were maintained when adjusting for these variables, with a dose-response effect. The beneficial effect of vitamin $\mathrm{D}$ supplementation on HRQoL was considered to be of "clinically significant magnitude" [77]. Lower annualized relapse rates were significantly associated with taking vitamin D supplementation vs. not taking supplements. The dose taken seemed to be of less importance. No effect on disability was found for either supplementation or deliberate sun exposure, but an increase of latitude by $1^{\circ}$ (farther from the equator) predicted increased odds of moderate or high disability [77].

Table 3 Self-reported average daily dose of supplemental vitamin $\mathrm{D}$ in an Internet survey among 2301 patients with MS. Originally published on BioMed Central, an open access journal, in [77]

\begin{tabular}{lll}
\hline Vitamin D dose & $\boldsymbol{N}$ & Percentage \\
\hline$>5000$ IU & 447 & 20.4 \\
2001-5000 IU & 734 & 33.5 \\
1-2000 IU & 613 & 28.0 \\
None & 399 & 18.2 \\
\hline
\end{tabular}


The large data set may compensate for some of the limitations of this study design. Vitamin D supplementation (along with all other measures) was self-reported and not validated with blood tests. No validated tool exists for quantifying variables like deliberate sun exposure; in this study, the question required simply a yes/ no answer [78]. Furthermore, there might be a selection bias in terms of the patients included, as respondents to such Internet surveys are patients who are typically very "engaged" with their situation and disease.

\section{Studies Contradicting the Benefit of Supplemental Vitamin D}

A study by Stein and colleagues is widely discussed among those not supporting vitamin D supplementation [72]. In this 6-month, doubleblind, placebo-controlled, randomized trial, patients were allocated to either high or low dose of vitamin D2. The high-dose regimen was $6000 \mathrm{IU}$ twice daily, the low-dose regimen 1000 IU daily. Twenty-three patients were included (11 in the treatment arm, 12 in the control group). There were no significant differences between the groups on the two primary endpoints-cumulative number of new $\mathrm{Gd}+$ lesions and change in the total volume of T2 lesions-nor were there differences on clinical outcome measures, such as number of relapses and effect on EDSS [72]. Neurology, in which the manuscript was published, ranked the study as providing class I evidence, but this rating is arguable. Although the study was double-blind, placebo-controlled, and randomized, the sample size was very small $(N=23)$. Moreover, there were withdrawals (two in the low-dose group, one in the high-dose group), and one patient from the low-dose group was partially excluded from MRI analyses due to brain surgery. Although the authors stated that the two groups were well matched, one patient (in the highdose group) had $38 \mathrm{Gd}+$ lesions at baseline, while all other patients had between two and five $\mathrm{Gd}+$ lesions at baseline. The low-dose group was, on average, 10.5 years older than the highdose group; importantly, the number of exacerbations in MS declines over time, biasing the data in favor of the low-dose group. In addition, this study compared low-dose and high-dose vitamin $\mathrm{D}$ administration and did not utilize a concurrent control group of subjects that did not receive any supplemental vitamin D. Finally, even though vitamin D2 seems to be a less potent form of vitamin D than vitamin D3 in all primate species [17], the 1000-IU/day regimen for the low-dose group is above what the IOM recommends in terms of daily intake [4] and both groups may have benefited from vitamin D supplementation.

In a 96-week, randomized, controlled trial designed to evaluate the effects of supplementation with 20,000 IU/week of vitamin D (averaged to approximately $2800 \mathrm{IU} /$ day) on bone mineral density in 35 MS patients, Kampman and colleagues found that consumption of vitamin $\mathrm{D}$ did not result in beneficial effects on the measured MS-related outcomes, which included annualized relapse rates. However, the study was not powered to address clinical outcomes [73]. The authors suggested that the low annualized relapse rate seen at baseline could have contributed to the absence of significant effects in this study. Study limitations included a small sample size $(N=68)$, which may be inadequate for assessing effects on clinical outcomes [73].

Furthermore, two studies from Iran did not find a beneficial effect of vitamin D supplementation on clinical or MRI outcome measures in patients with RRMS. Shaygannejad and colleagues studied 50 patients in a 12-month, randomized, double-blind, placebo-controlled, phase 2 clinical trial [74]. The 25 patients in the treatment group received $4000 \mathrm{IU} /$ day of vitamin $\mathrm{D}$ for the first 2 weeks and were thereafter escalated to $8000 \mathrm{IU} /$ day in addition to their disease-modifying agent. The control group $(n=25)$ was treated with placebo combined with disease-modifying therapy. In a separate study, Mosayebi and colleagues evaluated the effects of vitamin D3 supplementation at a dose of $300,000 \mathrm{IU} / \mathrm{month}$ vs. placebo in a randomized, prospective study with 62 patients [71]. Over the 6-month observation period, no differences between groups on either EDSS or Gd+ lesion count were observed, but immune-inhibitory transforming growth factor beta and 
interleukin 10 were significantly higher in the vitamin D-supplemented group compared with placebo [71].

Several of the studies above were included in a meta-analysis conducted by James and colleagues evaluating the effect of vitamin D-related intervention trials on MS relapses [85]. The five studies [22, 72-75] included 129 patients with high-dose vitamin D supplementations and 125 controls. Administered doses of vitamin D supplementations, study designs, patient populations, outcome parameters, and observation period were considerably variable among the assessed studies. Given these differences, the numerous limitations of each of these studies and the mixed reported study results, it is not surprising that the meta-analysis did not find a significant association between vitamin $\mathrm{D}$ treatment and the relative risk of relapse in MS [85]. In the view of the authors, "further larger and more prolonged studies...are merited" to better understand the role of vitamin D supplementation in MS [85].

\section{Ongoing Studies Evaluating the Role of Supplemental Vitamin D in MS}

A search of recently initiated and ongoing clinical studies evaluating the role of supplemental vitamin D in MS revealed the following:

- The Efficacy of Vitamin D Supplementation in Multiple Sclerosis (EVIDIMS) study (NCT01440062) $[86,87]$ is a German multicenter, stratified, randomized, controlled, double-blind, clinical phase 2 study. Eighty patients with CIS or MS whose disease courses were stable while taking IFNB-1b were randomized to receive either high-dose (on average, 10,200 IU/day) or low-dose (on average $200 \mathrm{IU} /$ day) vitamin D3 for 18 months as a supplement. The primary outcome measure is the number of new T2 lesions. Secondary endpoints include additional MRI and optical coherence tomography (OCT) parameters, clinical parameters, as well as cognition, fatigue, depression, and quality of life. Safety and tolerability of highdose vitamin $\mathrm{D}$ supplementation are additional outcome measures. This study is ongoing, and results are expected in 2018 or 2019.

- The Vitamin D to Ameliorate Multiple Sclerosis (VIDAMS) study (NCT01490502) $[88,90]$ is a randomized, controlled, phase 3 study that aims to include 172 patients in the US. After a run-in phase of 1 month on GA, patients will be assigned to low-dose (600 IU/day) vs. high-dose (5000 IU/day) vitamin D3 as an add-on therapy to GA. This academic study is currently recruiting patients and will terminate in 2018 [86, 88]. Clinical and MRI parameters will also be evaluated.

\section{SUMMARY AND CONCLUSIONS}

Evidence available to date suggests that the level of serum vitamin $\mathrm{D}$ affects the risk of developing MS and also modifies disease activity in MS patients. Until several years ago, evidence that higher levels of vitamin D are associated with favorable effects on MS risk and a reduction in MS activity was supported largely by observational studies. Limitations of these studies restricted confidence in a specific effect of vitamin D in MS. Newer data with Mendelian randomization analyses suggest there is a causal relationship between low vitamin D level and the risk of MS. Furthermore, post hoc evaluations from the phase 3 BENEFIT and BEYOND studies substantiate findings of observational trials. Across all trials, associations between 25(OH) levels and MS and its activity are generally stronger for MRI than for clinical outcomes, which may be due to the higher sensitivity of MRI compared to typical clinical parameters. Low or even insufficient $25(\mathrm{OH}) \mathrm{D}$ levels were common in many earlier cohorts. Patients in more recent studies have higher baseline vitamin D levels, potentially changing the immunopathology of MS and altering responses to some therapeutic drugs.

In aggregate, studies suggest that vitamin $\mathrm{D}$ supplementation may be beneficial for patients with MS and others. However, the study limitations identified in this review recognize the need for larger controlled clinical trials to 
establish vitamin D supplementation as the standard of care for MS patients. Though there is increasing evidence indicating that lower vitamin D levels are associated with increased risk of MS and greater clinical and brain MRI activity in established MS, the impact of vitamin D supplementation on MS activity remains inadequately investigated. There is no consensus on "sufficient" vitamin D levels. In the view of IOM, 25(OH)D levels greater than $50 \mathrm{nmol} / \mathrm{L}$ $(20 \mathrm{ng} / \mathrm{mL})$ are sufficient. The Endocrine Society argues for $75 \mathrm{nmol} / \mathrm{L}(30 \mathrm{ng} / \mathrm{mL})$ or higher, based on a medical model which takes into account skeletal and non-skeletal health. Numerous studies suggest that serum $25(\mathrm{OH}) \mathrm{D}$ levels of approximately $100 \mathrm{nmol} / \mathrm{L}(40 \mathrm{ng} / \mathrm{mL})$ are the lower limit for controlling MRI and clinical activity in patients with MS. More research is needed to establish the recommended levels of vitamin D supplementation necessary to reduce the risk for MS and MS clinical activity.

In conclusion, based on the data reviewed, identification and correction of vitamin D insufficiency with supplementation at recommended doses is a sensible clinical action/course/target/objective and one that provides a favorable risk-benefit profile for vitamin $\mathrm{D}$ for most patients with MS.

\section{ACKNOWLEDGEMENTS}

Funding. Funding for medical writing assistance, as well as any applicable article processing fees and Open Access fee was provided by Bayer HealthCare Pharmaceuticals.

Authorship. All named authors meet the International Committee of Medical Journal Editors (ICMJE) criteria for authorship for this manuscript, take responsibility for the integrity of the work as a whole, and have given final approval for the version to be published.

Writing Assistance. Editorial assistance in the preparation of this manuscript was provided by Staci Brandt, PA-C, MBA, MS and Maria Bavishi, MS from Global Prairie Marketing, LLC.
Disclosures. Martina B Sintzel, $\mathrm{PhD}$ has received consultancy fees from Bayer and Fresenius. Mark Rametta, D.O is employed by Bayer. Anthony T. Reder, MD has received unrestricted grant and clinical trials support from Bayer, Biogen, Novartis, Serono, and Teva.

Compliance with Ethics Guidelines. This article is based on previously conducted studies, and as such, and does not involve any new studies of human or animal subjects performed by any of the authors.

Data Availability. Data sharing is not applicable to this article as no datasets were generated or analyzed during the current study.

Open Access. This article is distributed under the terms of the Creative Commons Attribution-NonCommercial 4.0 International License (http://creativecommons.org/licenses/ by-nc/4.0/), which permits any noncommercial use, distribution, and reproduction in any medium, provided you give appropriate credit to the original author(s) and the source, provide a link to the Creative Commons license, and indicate if changes were made.

\section{REFERENCES}

1. Munger K, Levin L, Hollis B, Howard N, Ascherio A. Serum 25-hydroxyvitamin D levels and risk of multiple sclerosis. JAMA. 2006;296(23):2832.

2. Munger K, Ascherio A. Prevention and treatment of MS: studying the effects of vitamin D. Mult Scler J. 2011;17(12):1405-11.

3. Munger K, Åivo J, Hongell K, Soilu-Hänninen M, Surcel H, Ascherio A. Vitamin D status during pregnancy and risk of multiple sclerosis in offspring of women in the Finnish maternity cohort. JAMA Neurol. 2016;73(5):515.

4. Ross AC, Manson JE, Abrams SA, et al. The 2011 report on dietary reference intakes for calcium and vitamin $\mathrm{D}$ from the Institute of Medicine: what clinicians need to know. J Clin Endocrinol Metab. 2011;96:53-8.

5. ChemSpider | Search and share chemistry [Internet]. Chemspider.com. 2017 [cited 30 June 2016]. http://www.chemspider.com. 
6. Conlan R, Sherman E. Unraveling the enigma of vitamin D [Internet]. National Academy of Sciences; 2000 [cited 28 June 2016]. http://www. nasonline.org/publications/beyond-discovery/vita min-d.pdf.

7. Ascherio A, Munger K, Simon K. Vitamin D and multiple sclerosis. Lancet Neurol. 2010;9(6):599-612.

8. Holick M. Vitamin D: a millenium perspective. J Cell Biochem. 2002;88(2):296-307.

9. Health Quality Ontario. Clinical Utility of Vitamin D Testing: An Evidence-Based Analysis. 2010 p. 193.

10. Wacker M, Holick M. Vitamin D-effects on skeletal and extraskeletal health and the need for supplementation. Nutrients. 2013;5(1):111-48.

11. Holick M, Binkley N, Bischoff-Ferrari $\mathrm{H}$, et al. Evaluation, treatment, and prevention of vitamin D deficiency: an endocrine society clinical practice guideline. J Clin Endocrinol Metab. 2011;96(7):1911-30.

12. Yang L, Ma J, Zhang X, Fan Y, Wang L. Protective role of the vitamin $\mathrm{D}$ receptor. Cell Immunol. 2012;279(2):160-6.

13. Hossein-nezhad A, Holick M. Vitamin D for health: a global perspective. Mayo Clin Proc. 2013;88(7):720-55.

14. Mora J, Iwata M, von Andrian U. Vitamin effects on the immune system: vitamins $\mathrm{A}$ and $\mathrm{D}$ take centre stage. Nat Rev Immunol. 2008;8(9):685-98.

15. Pierrot-Deseilligny C, Souberbielle J. Contribution of vitamin $\mathrm{D}$ insufficiency to the pathogenesis of multiple sclerosis. Ther Adv Neurol Disor. 2013;6(2):81-116.

16. Ross A, Taylor C, Yaktine A, Del Valle H. Dietary reference intakes: calcium and vitamin D. Committee to review dietary reference intakes for vitamin $\mathrm{D}$ and calcium food and nutrition board [Internet]. Washington, D.C.: National Academy of Sciences; 2011 [cited 28 June 2016]. http://www. ncbi.nlm.nih.gov/books/NBK56070/pdf/TOC.pdf.

17. Houghton L, Vieth R. The case against ergocalciferol (vitamin D2) as a vitamin supplement. The Am J Clin Nutr. 2006;84(4):694-7.

18. Christakos S, Dhawan P, Liu Y, Peng X, Porta A. New insights into the mechanisms of vitamin D action. J Cell Biochem. 2003;88(4):695-705.

19. Holick M, Vitamin D. Deficiency. N Engl J Med. 2007;357(3):266-81.
20. Heaney R. Functional indices of vitamin D status and ramifications of vitamin D deficiency. Am J Clin Nutr. 2004;80(6):1706S-9S.

21. Heaney R, Davies K, Chen T, Holick M, Barger-Lux M. Human serum 25-hydroxycholecalciferol response to extended oral dosing with cholecalciferol. Am J Clin Nutri. 2003;77(1):204-10.

22. Burton J, Kimball S, Vieth R, et al. A phase I/II doseescalation trial of vitamin D3 and calcium in multiple sclerosis. Neurology. 2010;74(23):1852-9.

23. Kimball S, Ursell M, O'Connor P, Vieth R. Safety of vitamin D3 in adults with multiple sclerosis. Am J Clin Nutr. 2007;86(3):645-51.

24. Smolders J, Peelen E, Thewissen M, et al. Safety and $\mathrm{T}$ Cell modulating effects of high dose vitamin D3 supplementation in multiple sclerosis. PLoS One. 2010;5(12):e15235.

25. Bell D, Crooke M, Hay N, Glendenning P. Prolonged vitamin D intoxication: presentation, pathogenesis and progress. Int Med J. 2013;43(10):1148-50.

26. Fragoso Y, Adoni T, Damasceno A, et al. Unfavorable outcomes during treatment of multiple sclerosis with high doses of vitamin D. J Neurol Sci. 2014;346(1-2):341-2.

27. Swank R, Lerstad O, Strøm A, Backer J. Multiple Sclerosis in Rural Norway. $\mathrm{N}$ Eng J Med. 1952;246(19):721-8.

28. Westlund K. Distribution and mortality time trend of multiple sclerosis and some other diseases in Norway. Acta Neurol Scand. 1970;46(4-5):455-83.

29. van der Mei I, Ponsonby A, Blizzard L, Dwyer T. Regional variation in multiple sclerosis prevalence in Australia and its association with ambient ultraviolet radiation. Neuroepidemiology. 2001;20(3):168-74.

30. Vukusic S, Van Bockstael V, Gosselin S, Confavreux C. Regional variations in the prevalence of multiple sclerosis in French farmers. J Neurol Neurosurg Psychiatry. 2006;78(7):707-9.

31. Pierrot-Deseilligny C, Souberbielle J. Is hypovitaminosis $\mathrm{D}$ one of the environmental risk factors for multiple sclerosis. Brain. 2010;133(7):1869-88.

32. Orton S, Wald L, Confavreux C, et al. Association of UV radiation with multiple sclerosis prevalence and sex ratio in France. Neurology. 2011;76(5):425-31.

33. Kurtzke J, Beebe G, Norman J. Epidemiology of multiple sclerosis in US veterans: III. Migration and the risk of MIS. Neurology. 1985;35(5):672. 
34. Ascherio A, Munger K. Environmental risk factors for multiple sclerosis. Part II: noninfectious factors. Ann Neurol. 2007;61(6):504-13.

35. Lucas R, Ponsonby A, Dear K, et al. Sun exposure and vitamin $\mathrm{D}$ are independent risk factors for CNS demyelination. Neurology. 2011;76(6):540-8.

36. Hauser S, Weiner H, Che C, Shapiro M, Gilles F, Letvin N. Prevention of experimental allergic encephalomyelitis (EAE) in the SJL/J mouse by whole body ultraviolet irradiation. J Immunol. 1984;132(3):1276-81.

37. Willer C. Timing of birth and risk of multiple sclerosis: population based study. BMJ. 2005;330(7483):120.

38. Fiddes B, Wason J, Sawcer S. Confounding in association studies: month of birth and multiple sclerosis. J Neurol. 2014;261(10):1851-6.

39. Rodríguez Cruz P, Matthews L, Boggild M, et al. Time- and region-specific season of birth effects in multiple sclerosis in the United Kingdom. JAMA Neurol. 2016;73(8):954.

40. Munger K, Zhang S, O'Reilly E, et al. Vitamin D intake and incidence of multiple sclerosis. Neurology. 2004;62(1):60-5.

41. Nielsen N, Munger K, Stenager E, Ascherio A. Author response: neonatal vitamin D status and risk of multiple sclerosis: a population-based case-control study. Neurology. 2017;89(4):411.

42. Mokry L, Ross S, Ahmad O, et al. Vitamin D and risk of multiple sclerosis: a mendelian randomization study. PLOS Med. 2015;12(8):e1001866.

43. Gianfrancesco M, Stridh P, Rhead B, et al. Evidence for a causal relationship between low vitamin D, high BMI, and pediatric-onset MS. Neurology. 2017;88(17):1623-9.

44. Jelinek G. Determining causation from observational studies: a challenge for modern neuroepidemiology. Front Neurol. 2017;8:1-3.

45. Rhead B, Bäärnhielm M, Gianfrancesco $M$, et al. Mendelian randomization shows a causal effect of low vitamin D on multiple sclerosis risk. Neurol Gen. 2016;2(5):e97.

46. Ueda P, Rafatnia F, Bäärnhielm M, et al. Neonatal vitamin D status and risk of multiple sclerosis. Ann Neurol. 2014;76(3):338-46.

47. Ascherio A, Munger K. Not too late to take vitamin D supplements. Ann Neurol. 2014;76(3):321-2.
48. Pihl-Jensen G, Frederiksen J. 25-Hydroxyvitamin D levels in acute monosymptomatic optic neuritis: relation to clinical severity, paraclinical findings and risk of multiple sclerosis. J Neurol. 2015;262(7):1646-54.

49. Marrie R, Daumer M. A gestational dose of vitamin D per day keeps the MS doctor away. Neurology. 2016;88(1):13-4.

50. Runia T, Hop W, de Rijke Y, Buljevac D, Hintzen R. Lower serum vitamin D levels are associated with a higher relapse risk in multiple sclerosis. Neurology. 2012;79(3):261-6.

51. Mowry E, Krupp L, Milazzo M, et al. Vitamin D status is associated with relapse rate in pediatriconset MS. Ann Neurol. 2010;67(5):618-24.

52. Simpson S, Taylor B, Blizzard L, et al. Higher 25-hydroxyvitamin $\mathrm{D}$ is associated with lower relapse risk in MS. Ann Neurol. 2010;68(2):193-203.

53. Mowry E, Waubant E, McCulloch C, et al. Vitamin D status predicts new brain magnetic resonance imaging activity in multiple sclerosis. Ann Neurol. $2012 ; 72(2): 234-40$.

54. Mowry E, Pelletier D, Gao Z, Howell M, Zamvil S, Waubant E. Vitamin D in clinically isolated syndrome: evidence for possible neuroprotection. Eur J Neurol. 2015;23(2):327-32.

55. Smolders J, Menheere P, Kessels A, Damoiseaux J, Hupperts R. Association of vitamin D metabolite levels with relapse rate and disability in multiple sclerosis. Mult Scler J. 2008;14(9):1220-4.

56. Harandi A, Shahbeigi S, Pakdaman $H$, Fereshtehnejad S, Nikravesh E, Jalilzadeh R. Association of serum $25(\mathrm{OH})$ vitamin D3 concentration with severity of multiple sclerosis. Iran J Neurol [Internet]. 2012 [cited 22 August 2017];11(2):54-58. https://www.ncbi.nlm.nih.gov/pmc/articles/PMC38 29240/.

57. Shahbeigi S, Pakdaman H, Fereshtehnejad S, Jalilzadeh G, Heydari M. Serum Vitamin D3 Concentration Correlates with the Severity of Multiple Sclerosis. Int J Prev Med. 2013;4(5):585-91.

58. Martinelli V, Dalla Costa G, Colombo B, et al. Vitamin D levels and risk of multiple sclerosis in patients with clinically isolated syndromes. Mult Scler J. 2013;20(2):147-55.

59. Koven N, Cadden M, Murali S, Ross M. Vitamin D and long-term memory in multiple sclerosis. Cogn Behav Neurol. 2013;26(3):155-60. 
60. Ascherio A, Munger K, White R, et al. Vitamin D as an early predictor of multiple sclerosis activity and progression. JAMA Neurol. 2014;71(3):306-14.

61. Fitzgerald K, Munger K, Köchert K, et al. Association of Vitamin D Levels With multiple sclerosis activity and progression in patients receiving interferon Beta-1b. JAMA Neurol. 2015;72(12):1458.

62. Kappos L, Polman C, Freedman M, et al. Treatment with interferon beta-1b delays conversion to clinically definite and McDonald MS in patients with clinically isolated syndromes. Neurology. 2006;67(7):1242-9.

63. Kappos L, Freedman M, Polman C, et al. Effect of early versus delayed interferon beta- $1 \mathrm{~b}$ treatment on disability after a first clinical event suggestive of multiple sclerosis: a 3-year follow-up analysis of the BENEFIT study. Lancet. 2007;370(9585):389-97.

64. Kappos L, Freedman M, Polman C, et al. Long-term effect of early treatment with interferon beta- $1 b$ after a first clinical event suggestive of multiple sclerosis: 5-year active treatment extension of the phase 3 BENEFIT trial. Lancet Neurol. 2009;8(11):987-97.

65. McDonald W, Compston A, Edan G, et al. Recommended diagnostic criteria for multiple sclerosis: Guidelines from the international panel on the diagnosis of multiple sclerosis. Ann Neurol. 2001;50(1):121-7.

66. Taylor B, Moses H, Paul F, Suarez G, Rametta M. Treatment of multiple sclerosis-relationship between Vitamin $D$ and Interferon $\beta$-1b. Eur Neurol Rev. 2015;10(2):124.

67. Munger K, Köchert K, Simon K, et al. Molecular mechanism underlying the impact of vitamin $\mathrm{D}$ on disease activity of MS. Ann Clin Trans Neurol. 2014;1(8):605-17.

68. Stewart N, Simpson S, van der Mei I, et al. Interferon- and serum 25-hydroxyvitamin D interact to modulate relapse risk in MS. Neurology. 2012;79(3):254-60.

69. Rotstein D, Healy B, Malik M, et al. Effect of vitamin D on MS activity by disease-modifying therapy class. Neurol Neuroimmunol Neuroinflamm. 2015;2(6):e167.

70. Loken-Amsrud K, Holmoy T, Bakke S, et al. Vitamin $\mathrm{D}$ and disease activity in multiple sclerosis before and during interferon-treatment. Neurology. 2012;79(3):267-73.

71. Mosayebi G, Ghazavi A, Ghasami K, Jand Y, Kokhaei P. Therapeutic effect of vitamin D3 in multiple sclerosis patients. Immunol Invest. 2011;40(6):627-39.

72. Stein M, Liu Y, Gray O, et al. A randomized trial of high-dose vitamin D2 in relapsing-remitting multiple sclerosis. Neurology. 2011;77(17):1611-8.

73. Kampman M, Steffensen L, Mellgren S, Jørgensen L. Effect of vitamin D3 supplementation on relapses, disease progression, and measures of function in persons with multiple sclerosis: exploratory outcomes from a double-blind randomised controlled trial. Mult Scler J. 2012;18(8):1144-51.

74. Shaygannejad V, Janghorbani M, Ashtari F, Dehghan H. Effects of adjunct low-dose vitamin D on relapsing-remitting multiple sclerosis progression: preliminary findings of a randomized placebo-controlled trial. Mult Scler Int. 2012;2012:1-7.

75. Soilu-Hänninen M, Åivo J, Lindström B, et al. A randomised, double blind, placebo controlled trial with vitamin D3as an add on treatment to interferon $\beta-1 b$ in patients with multiple sclerosis. J Neurol Neurosurg Psychiatry. 2012;83(5):565-71.

76. Etemadifar M, Janghorbani M. Efficacy of high-dose vitamin D3 supplementation in vitamin D deficient pregnant women with multiple sclerosis: Preliminary findings of a randomized-controlled trial. Iran J Neurol. 2015;14(2):67-73.

77. Jelinek G, Marck C, Weiland T, Pereira N, van der Meer D, Hadgkiss E. Latitude, sun exposure and vitamin D supplementation: associations with quality of life and disease outcomes in a large international cohort of people with multiple sclerosis. BMC Neurol. 2015;15(1):1-6.

78. Laursen J, Søndergaard H, Sørensen P, Sellebjerg F, Oturai A. Vitamin D supplementation reduces relapse rate in relapsing-remitting multiple sclerosis patients treated with natalizumab. Mult Scler Rel Dis. 2016;10:169-73.

79. Darwish H, Haddad R, Osman S, et al. Effect of vitamin $\mathrm{D}$ replacement on cognition in multiple sclerosis patients. Sci Rep. 2017;7:45926.

80. Smolders J, Hupperts R, Vieth R, et al. High dose cholecalciferol (vitamin D3) oil as add-on therapy in subjects with relapsing-remitting multiple sclerosis receiving subcutaneous interferon $\beta$-1a. In: Presented at the European Committee for Treatment and Research in Multiple Sclerosis conference. London, England, September 14-17, 2016. Abstract S166.

81. Camu W, Pierrot-Deseilligny C, Hautecoeur P, et al. Cholecalciferol supplementation in relapsing multiple sclerosis patients treated with subcutaneous interferon beta-1a: a randomized, controlled trial. 
In: Presented at the European Committee for treatment and research in multiple sclerosis conference. London, England, September 14-17, 2016. Abstract P750.

82. Sotirchos E, Bhargava P, Eckstein C, et al. Safety and immunologic effects of high- vs low-dose cholecalciferol in multiple sclerosis. Neurology. 2015;86(4):382-90.

83. Fox R, Miller D, Phillips J, et al. Placebo-controlled phase 3 study of oral BG-12 or glatiramer in multiple sclerosis. N Engl J Med. 2012;367(12):1087-97.

84. Cohen J, Barkhof F, Comi G, et al. Oral fingolimod or intramuscular interferon for relapsing multiple sclerosis. N Engl J Med. 2010;362(5):402-15.

85. James E, Dobson R, Kuhle J, Baker D, Giovannoni G, Ramagopalan S. The effect of vitamin D-related interventions on multiple sclerosis relapses: a metaanalysis. Mult Scler J. 2013;19(12):1571-9.

86. ClinicalTrials.gov [Internet]. Clinicaltrials.gov. 2017 [cited 30 June 2016]. http://www.clinicaltrials. gov.

87. Dörr J, Ohlraun S, Skarabis H, Paul F. Efficacy of vitamin D supplementation in multiple sclerosis (EVIDIMS Trial): study protocol for a randomized controlled trial. Trials. 2012;13(15):1-6.

88. Bhargava $\mathrm{P}$, Cassard S, Steele $\mathrm{S}$, et al. The Vitamin D to ameliorate multiple sclerosis (VIDAMS) trial: Study design for a multicenter, randomized, double-blind controlled trial of vitamin $\mathrm{D}$ in multiple sclerosis. Contemp Clin Trials. 2014;39(2):288-93. 